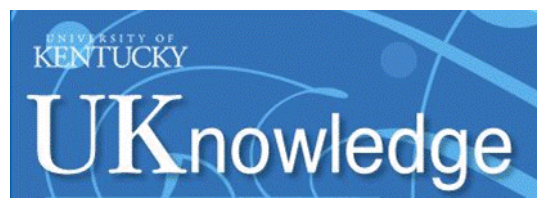

University of Kentucky

UKnowledge

Psychiatry Faculty Publications

Psychiatry

$1-2015$

\title{
Clinical Applications of CYP Genotyping in Psychiatry
}

\author{
Edoardo Spina \\ University of Messina, Italy \\ Jose de Leon \\ University of Kentucky, jdeleon@uky.edu
}

Follow this and additional works at: https://uknowledge.uky.edu/psychiatry_facpub

Part of the Psychiatry and Psychology Commons

Right click to open a feedback form in a new tab to let us know how this document benefits you.

\section{Repository Citation}

Spina, Edoardo and de Leon, Jose, "Clinical Applications of CYP Genotyping in Psychiatry" (2015).

Psychiatry Faculty Publications. 27.

https://uknowledge.uky.edu/psychiatry_facpub/27

This Article is brought to you for free and open access by the Psychiatry at UKnowledge. It has been accepted for inclusion in Psychiatry Faculty Publications by an authorized administrator of UKnowledge. For more information, please contact UKnowledge@lsv.uky.edu. 


\section{Clinical Applications of CYP Genotyping in Psychiatry}

Digital Object Identifier (DOI)

http://dx.doi.org/10.1007/s00702-014-1300-5

\section{Notes/Citation Information}

Published in Journal of Neural Transmission, v. 122, issue 1, p. 5-28.

(c) Springer-Verlag Wien 2014

The copyright holder has granted the permission for posting the article here.

The final publication is available at Springer via http://dx.doi.org/10.1007/s00702-014-1300-5 


\section{Journal of Neural Transmission (in press) \\ CLINICAL APPLICATIONS OF CYP GENOTYPING IN PSYCHIATRY}

Edoardo Spina ${ }^{1}$, Jose de Leon ${ }^{2}$

${ }^{1}$ Department of Clinical and Experimental Medicine, University of Messina, Messina, Italy; and ${ }^{2}$ University of Kentucky Mental Health Research Center at Eastern State Hospital, Lexington, KY, Psychiatry and Neurosciences Research Group (CTS-549), Institute of Neurosciences, University of Granada, Granada, Spain, and Biomedical Research Centre in Mental Health Net (CIBERSAM), Santiago Apóstol Hospital, University of the Basque Country, Vitoria, Spain.

Corresponding author: Prof. Edoardo Spina, Department of Clinical and Experimental Medicine, University of Messina, Policlinico Universitario, Via Consolare Valeria, 98125 Messina, ITALY Telephone: +390902213647 Fax: +390902213300 E-mail: espina@unime.it 


\begin{abstract}
A critical review of the limited available evidence and the authors' experience and judgment are used to summarize the role of cytochrome P450 (CYP) genetic variants in the pharmacokinetics of and clinical response to psychotropic medications. CYP1A2, CYP2B6, CYP2C9, CYP2C19, CYP2D6 and CYP3A4 genetic polymorphisms and their contributions to the metabolism of psychotropic drugs are reviewed. CYP1A2, CYP2B6 and CYP3A4 genotyping have limited current clinical utility. CYP2C9 genotyping has no utility in psychiatry. Psychiatrists should master tricyclic antidepressant (TCA) prescription, and if they use TCAs, they should have expertise in CYP2D6 and CYP2C19 genotyping and in TCA therapeutic drug monitoring (TDM) to safely dose TCAs. Practice guidelines recommend dose changes, TDM, or alternate drugs for: 1) CYP2C19 ultrarapid metabolizers (UM) taking citalopram or escitalopram; 2) CYP2C19 poor metabolizers (PMs) taking sertraline; 3) CYP2D6 PMs taking venlafaxine, aripiprazole, haloperidol, risperidone or zuclopenthixol; and 4) CYP2D6 UMs taking venlafaxine, aripiprazole, haloperidol, risperidone, zuclopenthixol or atomoxetine. According to the prescribing information, CYP2D6 PMs should receive $75 \%$ of the average long-acting aripiprazole dose and pimozide doses $>4 \mathrm{mg} /$ day should not be prescribed without CYP2D6 genotyping. In a situation of limited evidence, there is need to use the available pharmacological mechanistic information for better personalizing treatment in psychiatry. This is best done by combining CYP genotyping with TDM. Clozapine and risperidone concentration-to-dose (C/D) ratios are provided as two examples of this approach of how to integrate CYP genotyping and TDM in psychiatry. New studies are needed to verify that CYP2C19 PM genotyping may have potential to identify clozapine PMs and explain the lower clozapine metabolic capacity in East Asians.
\end{abstract}

Keywords: Cytochrome P-450 enzyme system; genetic testing; pharmacogenetics; practice guideline; psychopharmacology; psychotropic drug. 


\section{Introduction}

Many drugs including anxiolytics, antidepressants, antipsychotics and mood stabilizers are currently available to treat psychiatric disorders. As with most pharmacological agents, clinical response to psychotropic drugs varies considerably among patients treated with the same dose. Some patients obtain the desired clinical improvements, while others may exhibit problems with efficacy (partial or non-response) or with safety by suffering adverse drug reactions (ADRs). Nonpharmacological aspects, such as psychological and social implications, influence drug response but at the pharmacological level drug response results from the interaction of genetic, personal (e.g., age, sex, disease states) and environmental (e.g., smoking, diet, alcohol habits, concomitant medications) factors that produce interindividual differences in pharmacokinetics and pharmacodynamics (de Leon 2009).

Pharmacogenetics is the discipline dealing with genetically determined variation in how individuals respond to drugs. It is well recognized that therapeutic failure of drugs as well as serious ADRs in individuals or subpopulations of patients can each have a genetic component (Meyer 2004). Genetic factors may affect drug response at the level of drug-metabolizing enzymes, drug transporters, drug targets and other biomarker genes (Ingelman-Sundberg et al. 2007). Identification of these gene variants causing differences among patients may potentially allow "individualized" or "personalized" drug therapy.

Genetically-caused variability in drug metabolism is reflected in interindividual differences in clearance, half-life and plasma/serum concentrations of a given drug, usually called therapeutic drug monitoring (TDM). As most psychotherapeutic agents undergo extensive hepatic metabolism, differences in treatment outcome in psychiatric disorders may be attributed to predictable variations in genes encoding drug-metabolizing enzymes. Advances in pharmacogenetic research have led to the discovery of several polymorphisms associated with drug metabolism.

The aim of the present article is to summarize the available evidence clarifying the role of genetic variants of the cytochrome P450 (CYP) enzyme family, the most important phase I drugmetabolizing enzymes, in the pharmacokinetics of and clinical response to the most commonly used psychotropic medications and to critically review the implications of CYP genotyping techniques in psychiatry. Unfortunately, there has been limited funding for well-controlled studies to orient clinicians in the use of CYP genotyping in clinical work. Thus, the first section is this introduction. The second sections describe CYP genes. The third section on CYP isoforms and psychotropic drugs reviews the literature with an evidence-based medicine (EBM) approach. The third section reviews CYP isoforms in relation to psychotropic drugs (Table 1). The fourth section on the clinical utility of CYP genotyping in psychiatry describes the authors' experiences with CYP genotyping 
and provides a brief list of the guidelines that have been developed using an EBM approach (Table 2). In a situation of limited evidence, there is need to use the available pharmacological mechanistic information for better personalizing treatment in psychiatry, assuming that the best idea is to combine the approaches from EBM and personalized medicine (de Leon 2012). This is best done by combining CYP genotyping with TDM (Crettol et al. 2014). Therefore, the fifth section explains basic pharmacokinetic concepts (Table 3) to integrates CYP genotyping and TDM in psychiatry, and provides two examples of this approach, clozapine (Tables 4 and 5) and risperidone (Tables 6 and 7). Conclusions are provided in the sixth section.

\section{CYP genes}

Most psychotropic drugs are highly lipophilic agents subject to extensive biotransformation in the liver. Metabolic processes are necessary for converting a non-polar (lipid soluble) drug into one or more polar (water soluble) metabolites, facilitating their excretion in urine or bile. In general, the metabolism of psychotropic drugs includes initial phase I oxidative reactions, catalyzed by CYP enzymes, followed by phase II glucuronide conjugation, mediated by UDPglucuronosyltransferases (UGT) (Cozza et al. 2003).

The CYP system consists of a superfamily of more than 50 heme-containing monooxygenases, located in the membranes of the smooth endoplasmic reticulum in the liver and in many extrahepatic tissues; they are responsible for the phase I oxidative reactions of many drugs, nutrients, environmental toxins and endogenous substances (i.e., steroids, bile acids, fatty acids, prostaglandins) (Ingelman-Sundberg et al. 2007; Zanger and Schwab 2013). These enzymes are categorized into families and subfamilies according to similarities in their amino acid sequence, with each enzyme being designated as CYP followed by a number indicating the family, a letter indicating the subfamily, and another number denoting the specific isoform (Nelson 2009). The human genome comprises 57 CYP genes which are classified according to sequence homology into 18 families and 44 subfamilies. The CYP 1 to 3 families are involved in phase I drug metabolism, whereas CYPs 4 to 51 are associated with endobiotic metabolism (Ingelman-Sundberg et al. 2007; Nelson 2009).

The CYP isoenzymes playing a major role in the biotransformation of therapeutic agents are CYP1A2, CYP2B6, CYP2C9, CYP2C19, CYP2D6 and CYP3A4 (Ingelman-Sundberg et al. 2007; Zanger and Schwab 2013). Minor but clinically relevant isoforms include CYP2A6, CYP2C8 and CYP2E1. Each CYP isoform is a specific gene product and possesses a characteristic but relatively broad spectrum of substrate specificity. Different CYP isoforms may display overlapping substrate specificities (i.e., one CYP isoenzyme can metabolize multiple substrates and most substrates can 
be metabolized by various CYP isoenzymes). There is a large interindividual variability in the expression and activity of these isoenzymes deriving, not only from genetic, but also from nongenetic constitutional and environmental factors including concomitant administration of other drugs. Mutations or polymorphisms in genes coding for CYP isoforms can result in enzyme variants with higher, lower or no activity, or occasionally the total absence of the enzyme. A genetic polymorphism is defined as a stable variation in a given locus of the genetic sequence, which is detected in $1 \%$ or more of a specific population (Meyer 2004). These polymorphisms reflect gene insertions and deletions, gene duplications, copy number variations, and single nucleotide polymorphisms (SNPs), which can lead to decreased or elevated metabolism. The resulting phenotypes associated with these genetic variants are usually classified into four groups but, unfortunately for clinicians, not all articles (or laboratories providing genotyping) use the same terminology. Ingelman-Sundberg et al. (2007) defines them as:

- the poor metabolizers (PM), lacking functional enzymes due to defective or deleted genes;

- the intermediate metabolizers (IM), usually carrying 1 functional and 1 defective allele, but may also carry 2 partially defective alleles;

- the extensive metabolizers (EM), carrying 2 functional genes;

- the ultrarapid metabolizers (UM), with more than 2 active genes encoding a certain P450.

Most articles and laboratories agree that the term PM should be reserved for individuals who have no active CYP and that there are PMs related to CYP2C19 and CYP2D6. Currently, two mechanisms have been identified which explain UMs: the presence of at least 3 active genes in CYP2D6 or the presence of alleles with increased expression in CYP2C19 (see the CYP2C19 section). The IM phenotype causes the most conflict. Some IM subjects exhibit very low activity (sometimes called slow metabolizers); they are frequent in CYP2B6, CYP2C9 and CYP2D6 (see the respective sections). In CYP2D6 (and CYP2C19), some subjects have only one active allele and are classified as IM by Ingelman-Sundberg et al. (2007), but considered EM by others. To complicate things further, some CYP2D6 alleles display different activity for different drugs.

The activity of CYP enzymes can be evaluated by the use of phenotyping and/or genotyping tests (Sheffield and Phillimore 2009). Phenotyping procedures are based upon administration of a single dose of a probe compound to an individual, followed by measurement of urinary or serum concentrations of the test compound and its major metabolite(s). The ratio of parent drug/ metabolite (metabolic ratio, MR) is used as a measure of the activity of the enzyme responsible for the formation of that metabolite and is often referred to as an individual's phenotype. Probe drugs for in vivo phenotyping of CYP isoenzyme activity include caffeine for CYP1A2, bupropion for CYP2B6, tolbutamide for CYP2C9, omeprazole for CYP2C19, dextromethorphan for CYP2D6 and 
midazolam for CYP3A4 (Hiemke and Shams 2013). Genotyping is carried out through the use of molecular genetic testing allowing detection and characterization of allelic variants for the genes coding for the polymorphic enzymes. The obvious advantage of a genotyping test is that it represents a trait marker not influenced by environmental factors. The test can be performed in any situation and its result lasts a lifetime (Hiemke and Shams 2013). Phenotyping tests are contaminated by the medication the patient is taking and are not easy to use in the clinical environment unless one includes among them some of the TDM tests (e.g., some risperidone [de Leon et al. 2010] and venlafaxine [Preskorn et al. 2013] TDM ratios can be used to phenotype CYP2D6).

The clinical relevance of a CYP polymorphism depends on a number of factors, including the pharmacological and toxic activity of the parent compound and/or its metabolite(s), the therapeutic index of the drug, the overall contribution of the polymorphic pathway to the total clearance of the drug, the possible saturation of the polymorphic enzyme. The clinical consequences of polymorphic genes for drug-metabolizing enzymes may be more evident for subjects homozygous for defective genes (PMs), or for those with duplicated or amplified functional genes (UMs). In the former case, it is possible that the mutations cause diminished first pass metabolism, increased bioavailability, impaired elimination and, possibly, an exaggerated response. On the contrary, the UMs may not achieve therapeutic levels of the drug given at a standard dose and this might account for lack of therapeutic effect. The CYP polymorphisms that have the greatest clinical implications involve CYP2C9, CYP2C19 and CYP2D6. Phenotyping and/or genotyping should allow the identification of patients at risk of inefficacy or toxicity and offer tools to individualize drug prescription.

In recent years, the major CYP isoenzymes have been characterized at the molecular level and their various substrates, inhibitors and inducers have been identified (Rendic 2002; Cozza et al. 2003). As shown in Table 1, the majority of commonly used psychotropic drugs are metabolized by CYP enzymes and some may also act as inhibitors or inducers of one or more of these isoforms, thus resulting in metabolically-based drug interactions (Spina and de Leon, 2007; Spina et al. 2008; Preskorn et al. 2013; Spina and de Leon 2014; de Leon 2014a;b).

\section{CYP isoforms and psychotropic drugs}

Articles for this review were obtained from a PubMed search with no time limit. Searches were performed for psychotropic drugs. Only articles published in peer-reviewed journals were included, while meeting abstracts were excluded. Additional drug information was also obtained 
from citations of the articles that were retrieved during our search, and these were also included in our review. This search extended beyond the articles previously found and listed in the authors' published literature on CYP reviews and drug interaction studies and reviews.

This section summarizes the currently known evidence of the impact of genetic variants of the major CYP isoforms on the metabolism of and pharmacological response to psychotropic medications. There is no complete agreement in the literature on many of the issues discussed in this section, so the authors have presented their personal view after many years of reading and contributing to the literature and using CYP genotyping for clinical and research activities. Thus, it is possible that not all experts in the area may agree with the authors' interpretation of the literature, but the authors have provided references for their statements.

\subsection{CYP1A2}

CYP1A2 accounts for approximately $10-15 \%$ of total hepatic CYPs and is involved in the oxidative metabolism of many drugs, including theophylline, caffeine, tacrine, propranolol and a number of antidepressants (e.g., fluvoxamine, trazodone, duloxetine, mirtazapine and agomelatine) and antipsychotics (clozapine, olanzapine and asenapine) (Zhou et al. 2009). The interindividual variability in enzyme activity may be partly due to environmental factors which can be inhibitors, including fluvoxamine, or inducers, including cigarette smoking. The CYP1A2 gene, located on chromosome 15q24.1, is very well-conserved (Ingelman-Sundberg et al. 2007). To date, more than 21 variant alleles and a series of subvariants $(* 1 B$ to $* 21)$ of the $C Y P 1 A 2$ gene have been identified (Zanger and Schwab 2013). While some variants show decreased activity $(* 1 C, * 1 K, * 8, * 11, * 15$ and *16) (Sachse et al. 1999; Murayama et al. 2004; Soyama et al. 2005), the variant *1F is associated with increased inducibility among smokers (Sachse et al. 1999; Pavanello et al. 2005).

\section{Antidepressants}

CYP2D6 and, to a lesser extent, CYP1A2 appear to be the main isoforms responsible for the complex hepatic metabolism of the selective serotonin reuptake inhibitor (SSRI) fluvoxamine. A number of investigations have documented the effect of smoking (an inducer of CYP1A2) on fluvoxamine disposition (Carrillo et al. 1996; Katoh et al. 2010; Suzuki et al. 2011). A study in Japanese patients emphasized the influence of smoking on fluvoxamine serum levels, with no effect of the genetic variant being studied (rs2069514 or $-3860 \mathrm{G} / \mathrm{A}, \mathrm{G}>\mathrm{A}$ corresponds to $* 1 C$ allele) (Katoh et al. 2010).

CYP1A2 has been shown to be the main enzyme responsible for the metabolism of the new antidepressant agomelatine; thus the use of agomelatine is contraindicated in patients taking drugs 
strongly inhibiting this enzyme (e.g., fluvoxamine) (McAllister-Williams et al. 2010). CYP1A2 has also been shown to contribute to the demethylation of TCAs (Bertilsson et al. 2002; Bertilsson, 2007) and to the biotransformation of trazodone (Mihara et al. 2001).

In addition, CYP1A2 contributes to the metabolism of duloxetine and mirtazapine (Lantz et al. 2003; Stormer et al. 2000). Accordingly, lower serum concentrations of these antidepressants were observed in smokers than in nonsmokers (Fric et al. 2008; Lind et al. 2009). Nevertheless, to our knowledge, pharmacogenetic studies investigating the influence of CYP1A2 gene variants on their metabolism and on interaction with other drugs have not yet been performed.

\section{Antipsychotics}

CYP1A2 plays a major role in the metabolism of the newer antipsychotics clozapine (Eiermann et al. 1997), olanzapine (Ring et al. 1996) and asenapine (Ravyn et al. 2013), and participates in the biotransformation of the older agents haloperidol and thioridazine (Ravyn et al. 2013).

Clozapine is metabolized by CYP1A2, CYP2C19, CYP2D6, and CYP3A4 (Eiermann et al. 1997). While CYP1A2, CYP2C19, and CYP3A4 are involved in the metabolism of clozapine to Ndesmethylclozapine (norclozapine), CYP3A4 is responsible for its oxidation to clozapine N-oxide. CYP1A2 polymorphisms did not significantly affect individuals' clozapine metabolic capacity (Kootstra-Ros et al. 2005) although delays in response to clozapine were observed in individuals homozygous for the CYP1A2*F allele (Ozdemir et al. 2001; Eap et al. 2004). Higher serum concentrations of clozapine and its metabolite, $N$-desmethylclozapine, have been observed in patients carrying two CYPIA2 variants associated with reduced enzyme activity ( $-3860 \mathrm{~A}$, $-2467 \mathrm{del},-163 \mathrm{C},-739 \mathrm{G}$, and/or $-729 \mathrm{~T})$, compared with those with one or none (Melkersson et al. 2007).

The major metabolic pathways of olanzapine include direct $\mathrm{N}$-glucuronidation, mediated by UGT1A4, and N-demethylation, mediated by CYP1A2, while minor routes of olanzapine biotransformation include $\mathrm{N}$-oxidation, catalyzed by the flavin-containing mono-oxygenase-3 system, and 2-hydroxylation, metabolized by CYP2D6 (Ring et al. 1996; Linnet 2002). CYP1A2 seems to be an important enzyme in systemic exposure to olanzapine as suggested by some (Carrillo et al. 2003; Shirley et al. 2003), but not all, studies (Hägg et al. 2001). A study of patients with schizophrenia receiving olanzapine reported that $* 1 F / * 1 F$ genotype carriers displayed approximately $22 \%$ lower serum olanzapine concentrations (dose and bodyweight adjusted), independent of inducing factors (Laika et al. 2010). The new antipsychotic asenapine is cleared 
through oxidative metabolism, primarily by CYP1A2, and by direct glucuronidation (Ravyn et al. 2013).

\subsection{CYP2B6}

CYP2B6 contributes on average $\sim 2-5 \%$ to the total CYP hepatic pool (Zhou et al. 2009; Zanger and Schwab, 2013). This enzyme is primarily involved in the metabolism of the anticancer drugs cyclophosphamide and ifosfamide, the anti-HIV drugs efavirenz and nevirapine, the anesthetics propofol and ketamine, the atypical antidepressant and smoking cessation agent bupropion, and the $\mu$-opioid agonist methadone. The CYP2B6 gene has been mapped to chromosome 19 between $19 q 12$ and $19 q 13.2$ and is highly polymorphic. The variant alleles $C Y P 2 B 6^{*} 6$, $C Y P 2 B 6 * 16$ and $C Y P 2 B 6 * 18$ are associated with lower expression/activity, while the allele $C Y P 2 B 6 * 4$ appears to be associated with increased activity.

\section{Antidepressants}

In vitro studies have indicated that CYP2B6 is the main isoform involved in the biotransformation of bupropion (Hesse et al. 2000). Kirchheiner et al. (2003) found that $C Y P 2 B 6 * 4$ is associated with faster clearance of bupropion. In a recent genotype-guided study of 42 healthy subjects, $C Y P 2 B 6 * 6$ and $* 18$ gene variants were associated with approximately $33 \%$ reduced concentrations of hydroxybupropion at steady-state, with no effects on concentrations of bupropion or other metabolites (Benowitz et al. 2013).

\section{Addiction drugs}

Methadone, a synthetic $\mu$-opioid receptor agonist used for maintenance treatment in opioid addiction, can prolong the QT interval with risk for ventricular tachyarrhythmia and torsade de pointes (Crettol et al. 2014). Methadone is a chiral mixture of (R)-methadone, the major agonist of opioid receptors, and (S)-methadone, a weak agonist but a more potent blocker of the cardiac hERG (human ether-a-go-go-related gene) channel responsible for QT interval prolongation. Methadone is mainly metabolized by CYP2B6 and CYP3A4, whereas (S)-methadone is metabolized preferentially by CYP2B6 (Crettol et al. 2014). Different studies have documented that *6/*6 carriers had increased (S)-methadone serum levels leading to potentially higher risk of severe cardiac arrhythmias and methadone-associated deaths (Crettol et al. 2005; Eap et al. 2007; Bunten et al. 2011).

\subsection{CYP2C9}


CYP2C9 is one of the most abundant CYP enzymes in the human liver, representing approximately $20 \%$ of the hepatic total CYP content (Zhou et al. 2010). CYP2C9 is involved in the metabolism of about $15 \%$ of all drugs, mainly nonsteroidal anti-inflammatory drugs, oral antidiabetics, diuretics, angiotensin II receptor antagonists, anticancer drugs, oral anticoagulants (e.g., S-warfarin) and antiepileptics (e.g., phenobarbital and phenytoin). The CYP2C9 gene is located at chromosome 10q24 in a multigene cluster containing the other $C Y P 2 C$ subfamily members (CYP2C8, CYP2C18 and CYP2C19). CYP2C9 exhibits genetic polymorphisms and, to date, more than 35 allelic variants have been described (The Human Cytochrome P450 [CYP] Allele Nomenclature Committee, 2014). The two more common variants associated with reduced enzyme activity are $C Y P 2 C 9 * 2$ and $C Y P 2 C 9 * 3$.

All currently existing data suggest only a minor role for the CYP2C9 genetic polymorphism in the biotransformation of psychotropic drugs. The CYP2C9 enzyme has been shown to contribute to the metabolism of TCAs. In particular, the oral clearance of trimipramine, which was found to depend mainly on the CYP2D6 polymorphism, seems to be affected also by the CYP2C9 and CYP2C19 polymorphisms (Kirchheiner et al. 2003). Moreover, the CYP2C9 polymorphism seems to modulate the dose-corrected serum concentrations of fluoxetine and active moiety (fluoxetine plus norfluoxetine), together with the CYP2D6 gene variants (Llerena et al. 2004b; Scordo et al. 2005). CYP2C9 contributes by $20-30 \%$ to the metabolism of valproic acid, a commonly used antiepileptic drug and mood stabilizer. CYP2C9 also participates in the oxidation of the nonbenzodiazepine hypnotics zolpidem and zopiclone (Zhou et al. 2010).

\subsection{CYP2C19}

CYP2C19 is responsible for the metabolism of approximately $10 \%$ of commonly used drugs including proton pump inhibitors, clopidogrel and various psychotropic agents (Ingelman-Sundberg et al. 2007; Zhou et al. 2009). CYP2C19 is another important gene on chromosome 10q24.1-q24.3. The $C Y P 2 C 19$ gene is highly polymorphic; at least 35 allelic variants and subvariants $(* 1 B$ to $* 34)$ have been identified (Scott et al. 2011). CYP2C19*1, the wild-type allele encoding a fully functional enzyme, is present in double or single copy in EMs (homozygotes or heterozygotes, respectively). Heterozygous EMs are sometimes also referred to as IMs. The majority of the CYP2C19 PMs are carriers of the variant alleles $* 2$ and $* 3$, which are loss-of-function alleles, whereas the $* 17$ variant is associated with increased activity (Desta et al. 2002; Strom et al. 2012). There is a marked interethnic variation in the distribution of variant alleles (Scott et al. 2011; Martis et al. 2013). The allelic frequency of $C Y P 2 C 19 * 2$ has been shown to be $15 \%$ in Africans, $29-35 \%$ in Asians, $12-15 \%$ in Caucasians and $61 \%$ in Oceanians. The CYP2C19*3 is mainly found in 
Asians (5-9 \% in Asians, less than $0.5 \%$ in Caucasians). Scott et al. (2011) reported that 21\% of Europeans and $18 \%$ of Africans had one CYP2C19*17 allele. With these frequencies, it can be estimated that approximately $4 \%$ of Europeans and $3 \%$ of Africans would have two alleles with increased activity and may be considered CYP2C19 UMs (CYP2C19*17/CYP2C19*17).

Concerning psychoactive drugs, CYP2C19 is involved in the oxidative metabolism of a number of antidepressants including various TCAs and SSRIs and some benzodiazepines (Desta et al. 2002). The available studies are mainly focused on pharmacokinetics, whereas only a few investigated the possible association of genetic polymorphisms with clinical outcomes.

\section{Antidepressants}

The tertiary TCAs amitriptyline, imipramine and clomipramine are extensively metabolized by CYP2C19 to secondary amines, with contributions from CYP2C9, CYP3A4 and CYP1A2 (Bertilsson et al. 2002; Bertilsson 2007). The CYP2C19 polymorphisms seem to affect the Ndemethylation of amitriptyline in vivo (Jiang et al. 2002; Thieme et al. 2008). Serum concentrations of amitriptyline and the amitriptyline/nortriptyline ratio at steady-state were higher in subjects with two CYP2C19-mutated alleles $(* 2, * 3)$ compared with wild-type genotype both in Japanese psychiatric patients (Shimoda et al. 2002) and in Caucasians (Steimer et al. 2004; van der Weide 2005). Moreover, a study in a large sample of hospitalized patients documented that the CYP2C19*17 allele was significantly associated with decreased amitriptyline/nortriptyline ratio compared with the $C Y P 2 C 19 * 1 / * 1$ genotype (de Vos et al. 2011). Two pharmacokinetic studies in depressed Japanese patients reported higher plasma concentrations of imipramine and a lower desipramine/imipramine ratio in CYP2C19 PMs as compared to EMs (Koyama et al. 1996; Morinobu et al. 1997). Conversely, serum concentrations of imipramine were $30 \%$ lower in $C Y P 2 C 19 * 17 / * 17$ patients compared with $C Y P 2 C 19 * 1 / * 1$ individuals (Schenk et al. 2010). The steady-state serum concentrations of clomipramine have been shown to be affected by the CYP2C19 genotype (Yokono et al. 2001). In particular, patients with two mutated alleles had $41 \%$ and $76 \%$ higher dose- and weight-adjusted serum concentrations of clomipramine than individuals carrying one defective $C Y P 2 C 19$ allele or none, respectively.

Among SSRIs, citalopram and escitalopram are metabolized primarily by CYP2C19 and CYP3A4 and to a lesser extent by CYP2D6 (Spina et al. 2008). The metabolism of citalopram has been associated with CYP2C19 polymorphisms in Chinese subjects, both after a single dose (Yu et al. 2003) and at steady-state in a larger sample (Yin et al. 2006). Citalopram oral clearances in PMs were $43 \%$ and $33 \%$ lower compared with the homozygous and heterozygous EMs (Yin et al. 2006). For escitalopram as well, positive results were reported at steady-state (Tsai et al. 2010; Jin et al. 
2010) or after a limited number of doses in a smaller sample (Noher-Jensen et al. 2009). Concerning the $* 17$ allele, the escitalopram serum concentrations geometric mean was $42 \%$ lower in patients homozygous for $C Y P 2 C 19 * 17$ and 5.7-fold higher in subjects homozygous for defective CYP2C19 alleles, compared with the $C Y P 2 C 19 * 1 / * 1$ subgroup (Rudberg et al. 2008). The demethylation of sertraline to an almost inactive metabolite is mediated by different CYP isoforms, of which CYP2C19 is the most important. A single-dose study in healthy subjects reported that the area under the curve (AUC) of sertraline was 41\% higher in CYP2C19 PMs compared with EMs (Wang et al. 2001). However, due to the large therapeutic window of citalopram, escitalopram and sertraline, the influence of CYP2C19 variants on the clinical outcome with these antidepressants is marginal; Samer et al. (2013) considered that dose adjustments were not necessary.

For other SSRIs such as fluoxetine (Liu et al. 2001; Scordo et al. 2005) and fluvoxamine (Jan et al. 2002), and for the serotonin and noradrenaline reuptake inhibitor (SNRI) venlafaxine (Fukuda et al. 2000), the evidence of an association between pharmacokinetic parameters and CYP2C19 polymorphisms is weaker. CYP2C19 is also involved in the biotransformation of moclobemide, a reversible monoamine oxidase inhibitor; a single-dose study in Korean volunteers described a 3-fold higher AUC of moclobemide in PMs compared with homozygous EMs (Yu et al. 2001).

In conclusion, the CYP2C19 polymorphism appears to have only a marginal impact on the pharmacokinetics and clinical response to newer antidepressants, so the usefulness of CYP2C19 genotyping procedures as a guide for their individualization of dose is probably limited. Nevertheless, Kircheiner et al. (2004) suggested genotype-based dose reduction for citalopram and moclobemide in CYP2C19 PMs. Swen et al. (2011) recommended TDM and a dose increase by a factor of 1.5 in CYP2C19 UM patients taking citalopram or escitalopram and cutting the dose in half in CYP2C19 PMs taking sertraline.

\section{Benzodiazepines}

Some benzodiazepines, including diazepam and clobazam, are extensively metabolized by CYP2C19, with partial contribution from CYP2C18, CYP3A4, and CYP2B6 (Tiwari et al. 2009). Regarding diazepam, a study in patients receiving diazepam to treat preoperative anxiety showed that PMs of CYP2C19 take almost double the time of EMs to emerge from general anesthesia, presumably due to a $35 \%$ lower clearance of diazepam and thus prolonged sedation in these subjects (Inomata et al. 2005).

\section{Antipsychotics}


Recently Jaquenoud Sirot et al. (2009) found that five CYP2C19 PMs had 2.3-fold higher serum clozapine concentrations than patients with other CYP2C19 genotypes. This finding from a relatively small study may not appear important, but it might be crucial if one remembers that CYP2C19 PMs are frequent among East Asians. This may shed light on another neglected issue in the clozapine literature: that East Asians (Chang et al. 1997) have lower ability to metabolize clozapine (Table 4 and 5). In summary, the need is great for prospective studies of CYP2C19 genotyping and clozapine dosing.

\subsection{CYP2D6}

Although it accounts for less than 5\% of the hepatic total CYP content, CYP2D6 plays an important role in drug metabolism, being partially or entirely responsible for the oxidative biotransformation of commonly prescribed drugs such as antidepressants, antipsychotics, opioids, antiemetics, antiarrhythmics, beta-blockers, tamoxifen and atomoxetine (Zhou 2009a;b). Opioids such as codeine are pro-drugs, meaning that they are activated by CYP2D6. This is in contrast to other drugs including many antidepressants and antipsychotics, which are destroyed by CYP2D6.

The gene encoding for CYP2D6 is located in position 22q13.1 and is highly polymorphic. To date, more than 100 allelic variants and subvariants have been identified, and there are substantial ethnic differences in observed allele frequencies (Zhou 2009a). Some variants encode an inactive enzyme or no enzyme at all, while others consist of gene duplication. These gene variants are associated with various drug metabolism rates - individuals are classified as PMs, IMs, EMs or UMs according to their inherited genetic profile. PMs lack CYP2D6 activity and represent approximately $3 \%$ to $10 \%$ of Caucasians, but only $1 \%$ to $2 \%$ of East Asians. Among EMs, the catalytic activity varies largely, and a subgroup of subjects with extremely high enzyme activity has been classified as UMs. Three major mutated alleles, $C Y P 2 D 6 * 3, C Y P 2 D 6 * 4$ and $C Y P 2 D 6 * 5$, account for $90-95 \%$ of the PM alleles in Caucasians. Alleles with duplication or multiduplication of a functional $C Y P 2 D 6 * 2$ gene are associated with increased CYP2D6 activity: the frequency of this condition varies from 1-2 \% in Swedes to up to 7-10 \% in Spaniards and Southern Italians. Most of the CYP2D6 UMs probably have 3 active copies but as many as 13 copies have been described. A comprehensive worldwide study provided CYP2D6 UM frequencies of 1-5\% in Caucasians, $40 \%$ in northern Africa and $>20 \%$ in Oceania (Sistonen et al. 2007). East Asians frequently have one or two CYP2D6*10 alleles. In a study using a mathematical model to review pharmacokinetic studies, Tod et al. (2011) estimated that average individuals with CYP2D6*10/*10 had approximately $20 \%$ of the CYP2D6 activity of those with an active normal allele (CYP2D6*1). In an in vitro study Shen et al. (2007) estimated that, depending on the tested substrate, CYP2D6*10 had from $1 \%$ to $27 \%$ of 
the CYP2D6*1 activity (9\% for atomoxetine and 7\% for nortriptyline). CYP2D6*17 is found in individuals with African ancestry and usually expresses lower activity, but has normal activity for risperidone (de Leon et al. 2009a). Shen et al. (2007) estimated that, depending on the substrate, CYP2D6*17 had from $7 \%$ to $80 \%$ of the CP2D6*1 activity (22\% for atomoxetine and $36 \%$ for nortriptyline).

Unlike other CYPs, CYP2D6 is not inducible, and thus genetic mutations are largely responsible for the interindividual variation in enzyme expression and activity. On the other hand, CYP2D6 can be inhibited by several drugs, resulting in clinically significant drug interactions.

\section{Antidepressants}

Several antidepressants including TCAs, SSRIs and other newer agents are metabolized, at least in part, by CYP2D6 (Zhou 2009b).

First-generation TCAs have a relatively narrow therapeutic index and several studies support the existence of a relationship between their serum concentrations and clinical effects (Hiemke et al. 2011). They include tertiary amines (amitriptyline, imipramine, clomipramine) and secondary amines (nortriptyline, desipramine). Tertiary amines are demethylated to secondary amines, while both tertiary and secondary are further hydroxylated to active metabolites. In vivo and in vitro studies have indicated that the hydroxylation reactions of TCAs are catalyzed by CYP2D6, whereas N-demethylation is catalyzed by CYP2C19 and, to a lesser extent, by CYP1A2, CYP2C9 and CYP3A4 (Bertilsson et al. 2002; Bertilsson 2007). The best evidence of the impact of CYP2D6 genotype on elimination kinetics and steady-state serum concentrations has been found for the secondary amines nortriptyline and desipramine. In fact, due to the involvement of multiple CYP isoforms in their elimination, the magnitude of such relationships is reduced for tertiary amines. Significant interphenotypic differences in the kinetics of TCAs have been described in studies in healthy volunteers summarized in literature reviews (Bertilsson et al. 2002; Bertilsson 2007; Zhou, 2009b). In general, CYP2D6 PMs reach higher peak serum concentrations, and have lower clearances and longer half-lives as compared with CYP2D6 EMs. Interestingly, the elegant investigation by Dalen et al. (1998) showed that the number of active CYP2D6 gene copies had a strong impact on the pharmacokinetics of nortriptyline in healthy subjects. Moreover, earlier studies in depressed patients had documented a significant correlation between CYP2D6 activity and steady-state serum concentrations of imipramine (Brosen et al. 1986), nortriptyline (Dahl et al. 1996) or desipramine (Spina et al. 1997). A number of studies have investigated the influence of CYP2D6 variants on clinical outcomes in patients treated with TCAs. Several ADR cases with increased serum TCA concentrations in CYP2D6 PMs or therapeutic failure associated with 
decreased concentrations in CYP2D6 UMs have been documented (Bertilsson et al. 2002; Bertilsson 2007).

Over the past two decades, the SSRIs have become the antidepressants of first choice due to their better tolerability and safety profile as compared with TCAs. Unlike TCAs, SSRIs have a wide therapeutic index and no clear-cut correlation between serum levels and clinical response has been demonstrated. As a consequence, genetically- or environmentally-induced differences in their elimination are less likely to be of great clinical concern. Polymorphic CYP2D6 plays an important role in the metabolism of fluoxetine and paroxetine, and contributes to that of fluvoxamine and citalopram/escitalopram (Porcelli et al. 2011). Fluoxetine is N-demethylated to the active metabolite norfluoxetine by CYP2D6, with the additional contributions of CYP2C9, CYP2C19 and CYP3A4 (Spina et al. 2008). Significantly lower serum concentrations of fluoxetine (and norfluoxetine) in CYP2D6 EMs than in PMs at steady-state were found in Caucasians (Charlier et al. 2003; Llerena et al. 2004b), whereas other authors reported an effect of genotype only on S-enantiomer metabolism (Eap et al. 2001; Scordo et al. 2005). Paroxetine is extensively metabolized in the liver and at least 2 CYP isoforms are involved in its oxidation: the high affinity CYP2D6, whose saturation is responsible for the non-linear kinetics of the drug, and the low affinity CYP3A4. Several reports have described an association between the number of active alleles and paroxetine metabolism during a repeated dose regimen up to the steady state (Charlier et al. 2003; Sawamura et al. 2004; Ueda et al. 2006). CYP2D6 and CYP1A2 are the major CYP isoforms responsible for the metabolism of fluvoxamine. Studies investigating the possible correlation between CYP2D6 genetic polymorphisms and pharmacokinetic parameters of fluvoxamine produced conflicting results suggesting that the contribution of CYP2D6 to the overall clearance of fluvoxamine is marginal (Gerstenberg et al. 2003; Watanabe et al. 2008). Concerning citalopram and escitalopram, a singledose pharmacokinetic study reported an influence of CYP2D6 genotype on citalopram disposition (Fudio et al. 2010), whereas CYP2D6*4 and CYP2D6 gene duplication do not seem to influence the R:S ratios for citalopram and desmethylcitalopram (Carlsson et al. 2001).

Within the SNRI class, venlafaxine metabolism appears to be particularly influenced by CYP2D6 polymorphisms; in particular, CYP2D6 appears to play a major role in the formation of the active metabolite O-desmethylvenlafaxine (Eap et al. 2003; Whyte et al. 2006; Nichols et al. 2009). Since venlafaxine and its metabolite have similar pharmacological properties, the clinical implications of polymorphic venlafaxine metabolism are probably not relevant. However, venlafaxine cardiotoxicity (palpitation, shortness of breath, arrhythmia) has been reported in four patients, who were all PMs of CYP2D6 (Veefkind et al. 2000). The SNRI duloxetine is extensively metabolized in the liver primarily by CYP1A2 and, to a lesser extent, by CYP2D6 (Lantz et al. 
2003). Mirtazapine, one of the few noradrenergic and specific serotonergic antidepressants (NaSSA), has been studied in relation to CYP2D6 polymorphisms, as it is a substrate of this CYP isoenzyme.

An interesting relationship may exist between nonresponders to antidepressant therapy and the CYP2D6 UM phenotype. In this respect, two independent retrospective studies in patients treated with antidepressants mainly metabolized by CYP2D6, in particular TCAs and SSRIs, indicated a 5-10-fold higher-than-expected incidence of UMs among nonresponders (Rau et al. 2004; Kawanishi et al. 2004). This finding implies that nonresponse to antidepressant therapy due to ultrarapid metabolism of the drug is an important clinical issue and that a higher response rate could be obtained in a significant proportion of patients if dosing were based on the CYP2D6 pheno/genotype. Further prospective studies are needed to assess more precisely the cost-benefit ratio of pharmacogenetic individualization of therapy with antidepressants.

In conclusion, intensive research has demonstrated that most antidepressants are metabolized, at least in part, by the polymorphic CYP2D6. This explains the pronounced interindividual variability in serum concentrations of these agents and the interactions observed when these drugs are used in combination with other substrates or inhibitors of the enzyme. The clinical significance of this association is most pronounced for TCAs, as they have a small therapeutic index and their effects are concentration-dependent. Patients with a decreased capacity to eliminate these drugs, either due to a genetic or environmentally-induced deficiency in CYP2D6 may develop severe adverse effects with conventional doses. Conversely, UMs with duplicated or multiduplicated CYP2D6 genes may require higher than normal doses for optimal treatment. Therefore, genotyping for CYP2D6 may be used as a complement to determination of serum TCA concentrations when aberrant metabolic capacity (poor or ultrarapid) is suspected. In contrast, the impact of CYP2D6 polymorphisms on clinical outcome in patients treated with newer antidepressants remains to be demonstrated. Despite these considerations, specific dose recommendations based on CYP2D6 genotypes have been suggested for some antidepressants (Kirchheiner et al. 2001; Kirchheiner et al. 2004b; de Leon et al. 2006a; Swen et al 2011; Hicks et al. 2013). Kirchheiner et al. (2001) developed the first antidepressant dose recommendations based on CYP2D6 genotype/phenotype and pharmacokinetic parameters in Caucasians. The mean dose reduction was $50-80 \%$ for some TCAs in PMs, and $30 \%$ for some SSRIs. In UMs, the recommended increase in dose was $260 \%$ for desipramine and $230 \%$ for nortriptyline. More recently, Hicks et al. (2014) presented an updated version including CYP2D6 and CY2C19 genotyping that is described in Table 2. The Royal Dutch Association for the Advancement of Pharmacy established CYP2D6 genotype-based dose recommendations for several TCAs, SSRIs 
and SNRIs (Swen et al. 2011); Table 2 describes their recommendations for venlafaxine. No dose adjustment is recommended for paroxetine, duloxetine or mirtazapine. In general, there is good agreement that SSRIs are not good candidates for CYP2D6 (or any kind of CYP) genotyping (Matchar et al. 2006). This is not surprising to pharmacologists since SSRIs tend to exhibit no linear relationship between dosage and serum concentration, wide ranges between therapeutic and toxic doses, and some are powerful self-inhibitors of their metabolism (de Leon, 2008).

\section{Antipsychotics}

CYP2D6 plays an important role in the metabolism of various older and newer antipsychotics (Dahl 2002; Scordo and Spina, 2002; Zhou 2009b; Ravyn et al. 2013).

Concerning first-generation compounds, studies in patients and healthy volunteers have consistently shown a significant effect of CYP2D6 on the pharmacokinetic parameters of perphenazine (Dahl-Pustinen et al. 1989; Jerling et al. 1996; Linnet and Wiborg, 1996b; Ozdemir et al. 2007) and zuclopenthixol (Jerling et al. 1996; Linnet and Wiborg 1996a). CYP2D6, CYP3A4 and possible UGTs are the major routes for the complex metabolism of haloperidol (Fang et al. 2001; Katoh et al. 2012). Interestingly, subjects with CYP2D6 PM phenotype had higher serum concentrations, decreased clearance and longer half-life of haloperidol than EMs (Llerena et al. 1992; Suzuki et al. 1997; Mihara et al. 1999; Someya et al. 2003).

The metabolism of thioridazine to the active metabolite mesoridazine is mediated by both CYP2D6 and CYP3A4. A study involving 76 psychiatric patients documented that dose-corrected serum thioridazine concentrations were 1.8- and 3.8-fold higher ( $\mathrm{p}<0.01$ for both) in subjects with one or no active CYP2D6 alleles, respectively, compared with those with two or more functional alleles (Berecz et al. 2003).

It was thought that pimozide was primarily metabolized by CYP3A4 and to a lesser degree by CYP1A2 with no CYP2D6 contribution. More recently, drug interaction studies with CYP2D6 inhibitors have demonstrated that they can increase pimozide levels (Rogers et al. 2012). It has been estimated that doses >10 mg/day in CYP2D6 EMs and > $4 \mathrm{mg}$ /day in CYP2D6 PMs lead to high serum pimozide concentrations associated with risk for clinically-relevant QTc prolongation. Thus, the US prescribing information recommends CYP2D6 genotyping for prescribing pimozide doses > 4 mg/day (Rogers et al. 2012; Table 2).

Among newer antipsychotics, risperidone is converted by CYP2D6 and, to a lesser extent, by CYP3A4 to the active metabolite 9-hydroxyrisperidone or paliperidone, which is approximately equipotent with the parent drug in terms of dopamine receptor affinity, according to in vitro studies. Two studies in patients treated with risperidone found that the ratio of risperidone to 9- 
hydroxyrisperidone concentrations at steady-state was strongly associated with the CYP2D6 genotype, with the highest ratios in PMs and the lowest in UMs, but the sum of the active moieties was substantially comparable among the various genotype groups (Scordo et al. 1999; Roh et al. 2001), It might be assumed that CYP2D6 polymorphisms should have no relevant clinical implications for risperidone metabolism as decreased 9-hydroxyrisperidone production would be compensated for by higher serum levels of the parent drug, risperidone. However, some studies found that CYP2D6 PM patients experienced a higher incidence of ADRs, including lengthening of QTc interval, parkinsonism and discontinuation, presumably reflecting pharmacological differences between parent drug and metabolite (Bork et al. 1999; Kohnke et al. 2002; Llerena et al. 2004a; de Leon et al. 2005). Tables 6 and 7 describe how CYP genotyping and TDM can be integrated to better personalize risperidone dosing.

Aripiprazole is metabolized by CYP2D6 and CYP3A4 to its active metabolite dehydroaripiprazole, which has pharmacological properties similar to the parent drug. Aripiprazole is the major moiety in systemic circulation, while dehydroaripiprazole represents about $40 \%$ of aripiprazole exposure. Patients with the CYP2D6 PM phenotype have an $80 \%$ increase in aripiprazole exposure and a $30 \%$ decrease in dehydroaripiprazole exposure, resulting in a $60 \%$ higher exposure to the total active moieties; the elimination half-life of aripiprazole and dehydroaripiprazole increases significantly in PMs (Ravyn et al. 2013). The US long-acting aripiprazole prescribing information recommends monthly doses of $400 \mathrm{mg}$ in average individuals. The monthly dose should be $300 \mathrm{mg}$ in CYP2D6 PMs and $200 \mathrm{mg}$ in CYP2D6 PMs taking CYP3A4 inhibitors (Otsuka America Pharmaceutical, Inc. 2013).

CYP2D6 is the primary enzyme responsible for the metabolism of iloperidone. Conversely, polymorphic CYP2D6 plays only a minor role in the biotransformation of clozapine and olanzapine. Accordingly, a number of studies found no differences in steady-state serum concentrations of both antipsychotics in the various phenotype groups (Hägg et al. 2001; Melkersson et al. 2007; Nozawa et al. 2008, Cabaleiro et al. 2013; Söderberg and Dahl 2013).

A large number of studies have investigated associations between CYP2D6 polymorphisms, steady-state serum concentrations, and therapeutic and adverse effects of various antipsychotic medications (Scordo and Spina 2002; Ravyn et al. 2013). Results have been somewhat controversial and this may, at least partly, relate to differences in methodology (e.g., retrospective and prospective open-label studies as well as case-control studies), small sample size and heterogeneity of studied populations.

The impact of 25 genetic variants of drug metabolizing enzymes were investigated in a subset of patients $(n=750)$ who had participated in the large CATIE study and were treated with 
olanzapine, quetiapine, risperidone, ziprasidone, and perphenazine (Grossman et al. 2008). The study included assessment of polymorphisms associated with CYP2D6, CYP1A2, CYP3A4, CYP3A5, and aldehyde oxidase 1. None of the variants tested (including CYP2D6) showed a significant association with dosing, efficacy, overall tolerability, or tardive dyskinesia.

In conclusion, there is substantial evidence indicating a relationship between CYP2D6 genetic polymorphisms and the pharmacokinetic parameters of many antipsychotics such as perphenazine, haloperidol, pimozide, risperidone and aripiprazole. On the other hand, findings regarding the association between polymorphic CYP2D6 and response to these antipsychotics have been conflicting. Therefore, recommendations for dose adjustments of prescribed antipsychotics based on CYP2D6 may be premature, although there are some published recommendations for some antipsychotics (Table 2).

\section{Atomoxetine}

Atomoxetine, a noradrenaline reuptake inhibitor approved for the treatment of attentiondeficit/hyperactivity disorder, is predominantly metabolized by CYP2D6. There are no large CYP2D6 genotyping studies on atomoxetine response by independent investigators. The pharmaceutical company focused on the randomized clinical trials (RCTs) on CYP2D6 PMs and safety, while it should have focused on lack of efficacy in CYP2D6 UMs (de Leon 2007). The US prescribing information 1) recommends lower doses for CYP2D6 PMs or those taking CYP2D6 inhibitors despite CYP2D6 PMs experiencing better efficacy with limited ADRs; 2) makes no comment on the need for CYP2D6 genotyping before prescribing atomoxetine; and 3) does not comment on CYP2D6 UMs, who were not separated as a group in the RCTs. In summary, atomoxetine is a wide-therapeutic-window drug in which prescribing approximately 10-timeshigher doses in EMs should be safe; new studies are needed to establish whether or not higher doses are required for CYP2D6 UMs who may not respond to recommended doses (de Leon 2007).

\subsection{CYP3A4}

CYP3A4 is the most abundant CYP isoform, accounting for approximately $30 \%$ of total CYP in the human liver and $70 \%$ in the small intestine; it participates in the biotransformation of over 50\% of prescription drugs (Shimada et al. 1994; Ingelman-Sundberg et al. 2007). Drugs primarily metabolized by CYP3A4 include immunosuppressants (e.g., cyclosporin and tacrolimus), non-sedating antihistamines (e.g., terfenadine and astemizole), calcium antagonists (e.g., diltiazem, verapamil, nifedipine and other dihydropyridines), cholesterol lowering drugs (e.g., simvastatin and lovastatin), antiarrhythmics (e.g., amiodarone and quinidine), and several steroids (e.g., cortisol, 
ethinylestradiol and levonorgestrel). CYP3A4 plays an important role also in psychopharmacotherapy as it contributes to the biotransformation of various antidepressants (TCAs, sertraline, citalopram, escitalopram, venlafaxine, mirtazapine, reboxetine), antipsychotics (haloperidol, pimozide, clozapine, quetiapine, risperidone, aripiprazole, ziprasidone, lurasidone), mood stabilizers (carbamazepine) and benzodiazepines (e.g., alprazolam, midazolam and triazolam). The gene encoding for CYP3A4 is located on chromosome 7q21-q22.1 along with the other members of the CYP3A sub-family (CYP3A4, CYP3A5, CYP3A7 and CYP3A43). Several polymorphisms of CYP3A4 have been characterized, but most are low frequency and occur as heterozygotes with the wild-type allele, while others have no demonstrable effect on substrate metabolism (Ozdemir et al. 2000). Only the variants CYP3A4*6, CYP3A4*17, CYP3A4*20 and CYP3A4*22 display functional variability with decreased activity, whereas CYP3A4*18A is associated with increased activity (Dai et al. 2001; Ingelman-Sundberg et al. 2007). CYP3A4 is very sensitive to potent inducers including rifampin and antiepileptic inducers. St John's wort is a mild inducer. There are many CYP3A4 inhibitors; ketoconazole and erythromycin are among the most potent ones.

CYP3A4 is the major enzyme responsible for the metabolism of the newer antipsychotics quetiapine and lurasidone. To date, there is limited evidence of an association between these variants and antipsychotic response. A recent study in 238 patients treated with quetiapine found that dose-corrected serum concentrations of quetiapine were $67 \%$ higher $(p=0.01)$ in carriers of the CYP3A4*22 allele $(* 1 / * 22$ and $* 22 / * 22, \mathrm{n}=31)$ than in wild-type patients $(\mathrm{n}=207)$ (van der Weide and van der Weide 2014).

CYP3A4 is the primary enzyme responsible for the epoxidation of the antiepileptic and mood stabilizer, carbamazepine. A recent study in 90 epilepsy patients, both Caucasians and African-Americans, found that the $C Y P 3 A 4^{*} 1 B$ was associated with lower carbamazepine clearance (Puranik et al. 2013). However, this was observed in the combined cohort and not after segregation by race. As $C Y P 3 A 4 * 1 B$ occurs with higher frequency among African-Americans (0.61) as compared with Caucasians (0.08), the observed association might be due to race and not the SNP.

\section{Clinical utility of CYP genotyping in psychiatry}

Personalized prescription, the technical name for personalizing pharmacological treatments, can be expressed as personalizing dosing and/or drug selection (de Leon 2009). CYP genotyping can be used to personalize dosing for outliers, PMs and EMs. At present, CYP genotyping is mainly performed when efficacy (non-response) or safety (ADRs or abnormal TDM) problems occur. 
However, advances in genotyping technology and decreases in cost may in the immediate future make possible comprehensive genotyping, including CYP genotyping which could be completed before any psychiatric medication is prescribed (Crettol et al. 2014).

CYP1A2, CYP2B6 and CYP3A4 may be of interest for psychiatric and psychopharmacological researchers, but presently they have limited clinical utility for several reasons: 1) very few studies with significant findings exist and they are frequently unreplicated; 2) the relationships between phenotypes-genotypes are poorly understood; 3) and environmental factors are probably much more important that genetic variations.

Table 2 summarizes the comprehensive pharmacogenetic guidelines that have been developed for CYP2C19 and CYP2D6 and the related dosing of some psychiatric drugs (Hicks et al. 2013; Otsuka America Pharmaceutical, Inc. 2013; Swen et al. 2011).

Most antidepressants are being prescribed by general practitioners, including family doctors and internists. For treating more difficult cases psychiatrists need expertise in using genotyping to better prescribe antidepressants in two situations: when using TCAs and when treating rare individuals who are PMs for both CYP2C19 and CYP2D6.

Expertise in prescribing TCAs may be a "niche" skill that psychiatrists need to master; if they use TCAs, they should have expertise in CYP genotyping (Hicks et al. 2013) and TCA TDM (Preskorn 1989) to prescribe them safely. Furthermore, depression experts are firmly convinced that severe cases of major depression, melancholia type, respond better to TCAs than to newer antidepressants (Parker et al. 2010).

Very rare individuals $(<1 / 1000)$ are PMs for both CYP2C19 and CYP2D6. These subjects, who are missing both CYPs, should have problems metabolizing TCAs and most of the newer antidepressants (Johnson et al. 2006), but they should have no problem with mirtazapine (metabolized by multiple enzymes) or bupropion (metabolized by CYP2B6).

Clinicians need to be familiar with current genotyping methods and the next generation of sequencing technologies. Samer et al. (2013) describe current standardized methods available for the most important kinds of CYP genotyping needed by psychiatrists, that of CYP2D6 and CYP2C19. The AmpliChip CYP450 GeneChip is the best studied (de Leon 2006; de Leon et al. 2006b). Unfortunately for clinicians, many clinical laboratories develop their own genotyping methods for CYP2D6 and CYP2C19 and provide results based on their own understanding of the phenotypes. Unless the clinician is thoroughly familiar with activity of the various alleles and asks questions, it may be difficult to know whether the results for a specific patient are reliable and valid. Clinicians may want to select one laboratory and become familiar with the strengths and weaknesses of its technique. They need to remember that, although CYP2D6 and CYP2C19 
genotype-phenotype relationships are relatively well understood, rare new unusual alleles are still being discovered. To better interpret CYP2D6 or CYP2C19 genotyping, clinicians should complete a thorough pharmacological history and, if possible, have TDM results. If the physician does not have enough pharmacological expertise, consultation with a pharmacist and/or clinical pharmacologist may be a good idea.

The new next-generation sequencing technologies have enabled the characterization of human genetic variation on a scale that has not been possible until recently, which has helped establish the important role that rare variations may also play in drug response (Drögemöller et al. 2014). However, it appears that CYP (and other pharmacogenetic genes) are not well suited for the next-generation sequencing because of the genomic complexities (Drögemöller et al. 2013). Moreover, rare CYP variants may be particularly important in African populations where there is notable discordance between CYP genotypes and phenotypes (Alessandrini et al. 2013). In summary, how to make CYP rare variants and next-generation sequencing technologies useful to clinicians in the clinical environment has not yet been well-established (Drögemöller et al. 2014).

As genetic technology rapidly progresses, the cost of genetic testing in general, and CYP genotyping in psychiatry, is being drastically reduced. A recent review in pharmacogenomics found two types of cost studies (cost-effectiveness studies and cost-utility studies) but no corresponding published study in psychiatry (Wong et al. 2010). It was easier to probe the cost-effectiveness of CYP testing in psychiatry when the old antipsychotics and antidepressants were the main drugs prescribed in psychiatry, as they have a narrow therapeutic window and are highly dependent for their metabolism on CYP2D6 and CYP2C19, which are characterized by having PMs and UMs (Chou et al. 2000). The newer psychiatric drugs are characterized by wider therapeutic windows and more varied metabolic pathways, making it difficult to complete cost studies in CYP genotyping in psychiatry. Therefore, the large prospective studies necessary for establishing the classical proof of concept as well as the cost-benefit ratio of CYP genotyping in psychiatry will not occur, due to very high costs and lack of funding mechanisms. Retrospective proof-of-concept studies with comparisons to historical data are more likely to be used in the future to demonstrate the validity of pharmacogenomics in specific contexts (Crettol et al. 2014), including CYP genotyping in psychiatry.

\section{Integrating CYP genotyping and TDM in psychiatry}

As indicated in the prior section, CYP genotyping is being used mainly to personalize dosing. To personalize dosing in the clinical environment, one should include not only genetic but 
also environmental (inhibitors and inducers) and personal (e.g., age, gender, illnesses) variables (de Leon, 2009). TDM remains essential, as it reflects the influence of environmental and personal factors involved in metabolism, as well as the transport of drugs and the measurement of active metabolites (Crettol et al. 2014).

Psychiatric researchers are increasingly combining new pharmacogenomic findings with TDM. The combination of CYP genotyping and TDM may be moving to clinical practice in the immediate future in order to improve the safety and efficacy of pharmacotherapy of some psychiatric drugs (Crettol et al. 2014). A group of European psychiatrists has published the most comprehensive TDM guidelines in psychiatry (Hiemke et al. 2011); easier-to-read articles focused on antidepressants (Ostad Haji et al. 2012) and antipsychotics (Hiemke and Pfuhlmann 2012) are also available. The relationship between TDM and CYP genotypes have been described for clobazam and CYP2C19 PMs (de Leon et al. 2013), risperidone and CYP2D6 PMs and UMs (de Leon et al. 2007; 2009a), and venlafaxine and CYP2D6 PMs (Preskorn et al. 2013).

To understand how to combine CYP genotyping and TDM to personalize clozapine and risperidone dosing, two pharmacological concepts explained in Table 3 must be discussed: linear kinetics and the concentration/dose (C/D) ratio (Table 3).

The authors think that well-controlled single-dose drug trials in healthy volunteers do not properly reflect clinical activity; they prefer TDM studies in real patients with repeated dosing (de Leon et al. 2009b). These types of studies have allowed combining: 1) clozapine TDM and CYP2C19 (Table 4 and 5) and 2) risperidone TDM and CYP2D6 genotyping (Table 6; de Leon et al. 2010). Moreover, this has led to personalized clozapine dosing (Table 5; de Leon et al. 2009c) and risperidone dosing (Table 7).

The large prospective RCTs needed to establish the classical proof of concept, as well as the cost-benefit ratio of CYP2C19 genotyping in clozapine and CYP2D6 genotyping in risperidone, are not likely to take place due to the very high costs and the lack of funding mechanisms. Clozapine and risperidone are two preliminary examples of how to combine CYP genotyping and TDM. To be clinically useful in the future, pharmacogenetic testing may need to include epigenetic factors and become part of a complex puzzle, compiled with comprehensive pharmacological knowledge of the drug. It would include pharmacokinetics and pharmacodynamics, therapeutic window, idiosyncratic and dose-related ADRs, and would be used in association with TDM and other phenotyping tests (Crettol et al. 2014).

\section{Conclusions}


This article summarizes the available evidence describing the role of CYP genetic variants in pharmacokinetics and clinical response to the most commonly used psychotropic medications. It critically reviews the implications of CYP genotyping techniques in psychiatry. As there have been limited replicated findings from well-controlled studies to orient clinicians in the use of CYP genotyping in clinical work, the authors have focused on the available EBM data, but have also used their experience and judgment to try to best interpret the limited literature for clinicians. CYP1A2, CYP2B6, CYP2C9, CYP2C19, CYP2D6 and CYP3A4 genetic polymorphisms and their contributions to the metabolism of psychotropic drugs are thoroughly reviewed. CYP1A2, CYP2B6 and CYP3A4 genotyping may be of interest for psychiatric and psychopharmacological researchers, but have limited clinical utility at present for clinicians. CYP2C9 can be used for clinical testing but has no utility in psychiatry. CYP2D6 and CY2C19 genotyping are the most important kinds of CYP genotyping for psychiatrists. Recommendations from practice guidelines describing CYP2D6 and CY2C19 genotyping for dosing several psychiatric drugs were reviewed in detail (Table 2).

TCAs have a narrow therapeutic window and pose substantial risk of ADRs, including potentially lethal arrhythmias that are dose-related. Therefore, ADRs are much more likely to occur in CYP2D6 and CYP2C19 PMs, but may be more active for severe cases of major depression (Parker et al. 2010). Thus, expertise with TCAs may be a "niche" skill that psychiatrists need to master and if they use TCAs, they should have expertise in CYP2D6 and CYP2C19 genotyping (Hicks et al. 2013) and TDM (Preskorn, 1989; Ostad et al. 2012) to dose TCA safely.

For venlafaxine, practice guidelines recommend prescribing another antidepressant or using TDM in CYP2D6 PMs and increasing doses by a factor of 1.5 in CYP2D6 UMs (Swen et al. 2011). Practice guidelines recommend TDM and increasing doses by a factor of 1.5 in CYP2C19 UM patients taking citalopram or escitalopram; the dose should be halved in CYP2C19 PMs taking sertraline (Swen et al. 2011). Very rare individuals $(<1 / 1000)$ who do not have CYP2C19 or CYP2D6 (PMs for both isoenzymes) have problems metabolizing TCAs and most, but not all, of the newer antidepressants.

For aripiprazole, haloperidol, risperidone, or zuclopenthixol, the dose should be reduced by $50 \%$ in PMs or an alternative drug selected; whereas in UMs clinicians should monitor with TDM or select an alternative drug (Swen et al. 2011). The respective long-acting aripiprazole dose in CYP2D6 PMs and CYP2D6 PMs taking CYP3A4 inhibitors should be $75 \%$ and $50 \%$ of the average dose (Otsuka America Pharmaceutical, Inc., 2013). The US prescribing information recommends CYP2D6 genotyping for prescribing pimozide doses $>4 \mathrm{mg}$ /day since CYP2D6 PMs should not take doses $>4$ mg/day (Rogers et al. 2012; Table 2). 
Clinicians may need to be aware that normal atomoxetine doses may not be enough for CYP2D6 UMs (de Leon 2008; Swen et al. 2011). Diazepam and clobazam clearance may be impaired in CYP2C19 PMs, but benzodiazepines are wide therapeutic window drugs.

When the evidence is limited, using the available pharmacological mechanistic information is necessary for better personalizing treatment in psychiatry. The best idea may be to combine the approaches of EBM and personalized medicine (de Leon 2012), which can be accomplished best by combining CYP genotyping with TDM (Crettol et al. 2014). For most antipsychotics and many antidepressants, a linear relationship exists between typical doses and serum concentrations. This means that the relationship between concentration and dosing is stable; it does not change with various doses or concentrations, and the C/D ratio is constant. This $\mathrm{C} / \mathrm{D}$ ratio is a measure of the ability to eliminate the drug and is influenced by genes but also by environmental factors. Inducers decrease the $C / D$ ratio and inhibitors increase the $C / D$ ratio. Sometimes the $C / D$ ratio can be influenced by personal factors. For example, drugs eliminated as active compounds in the urine, geriatric age or renal insufficiency can increase the $C / D$ ratio. Clozapine and risperidone $C / D$ ratios are provided as two examples for approaching the integration of CYP genotyping and TDM in psychiatry. New studies are needed to verify whether CYP2C19 PM genotyping has the potential to identify clozapine PMs and account for the lower clozapine metabolic capacity in East Asians.

\section{Acknowledgments}

The authors acknowledge Lorraine Maw, M.A., and Margaret T. Boden, R.N., M.L.T., at the Mental Health Research Center at Eastern State Hospital, Lexington, KY, USA, who helped in editing the article.

\section{Conflict of interest}

No commercial organizations had any role in the writing of this paper for publication. In the past few years, Dr. Spina has participated in speakers/advisory boards and lectures supported by AstraZeneca, Bristol-Myers, Eli Lilly \& Co, Janssen Pharmaceuticals, Lundbeck and Pfizer. Dr. de Leon personally develops his presentations for lecturing, has never lectured using any pharmaceutical or pharmacogenetic company presentations, and has never been a consultant for pharmacogenetic or pharmaceutical companies. In the past, Dr. de Leon received researcherinitiated grants from Eli Lilly (one ended in 2003 and the other, as co-investigator, ended in 2007); from Roche Molecular Systems, Inc. (ended in 2007); and, in a collaboration with Genomas, Inc., from the NIH Small Business Innovation Research program (ended in 2010). He has been on the advisory boards of Bristol-Myers Squibb (2003/04) and AstraZeneca (2003). Roche Molecular 
Systems supported one of his educational presentations, which was published in a peer-reviewed journal (2005). His lectures were supported once by Sandoz (1997), twice by Lundbeck (1999 and 1999), twice by Pfizer (2001 and 2001), three times by Eli Lilly (2003, 2006, and 2006), twice by Janssen (2000 and 2006), once by Bristol-Myers Squibb (2006), and seven times by Roche Molecular Systems, Inc. (once in 2005 and six times in 2006). 


\section{References}

Alessandrini M, Asfaha S, Dodgen TM, Warnich L, Pepper MS (2013) Cytochrome P450 pharmacogenetics in African populations. Drug Metab Rev 45:253-275

Benowitz NL, Zhu AZX, Tyndale RF et al (2013) Influence of CYP2B6 genetic variants on plasma and urine concentrations of bupropion and metabolites at steady state. Pharmacogenet Genomics 23:135-141

Berecz R, de la Rubia A, Dorado P et al (2003) Thioridazine steady-state plasma concentrations are influenced by tobacco smoking and CYP2D6, but not by the CYP2C9 genotype. Eur J Clin Pharmacol 59:45-50

Bertilsson L (2007) Metabolism of antidepressant and neuroleptic drugs by cytochrome P450s: clinical and interethnic aspects. Clin Pharmacol Ther 82:606-609

Bertilsson L, Dahl ML, Dalen P, Al-Shurbaji A (2002) Molecular genetics of CYP2D6: clinical relevance with focus on psychotropic drugs. Br J Clin Pharmacol 53:111-122

Bork JA, Rogers T, Wedlund PJ, de Leon J (1999) A pilot study on risperidone metabolism: the role of cytochromes P450 2D6 and 3A. J Clin Psychiatry 60:469-476

Brosen K, Klysner R, Gram LF et al (1986) Steady-state concentrations of imipramine and its metabolites in relation to the sparteine/debrisoquine polymorphism. Eur J Clin Pharmacol 30:679-684

Bunten H, Liang WJ, Pounder D et al (2011) CYP2B6 and OPRM1 gene variations predict methadone-related deaths. Addict Biol 16:142-144

Cabaleiro T, López-Rodríguez R, Ochoa D et al (2013) Polymorphisms influencing olanzapine metabolism and adverse effects in healthy subjects. Hum Psychopharmacol 28:205-214

Carlsson B, Olsson G, Reis M et al (2001) Enantioselective analysis of citalopram and metabolites in adolescents. Ther Drug Monit 23:658-664

Carrillo JA, Dahl ML, Svensson JO et al (1996) Disposition of fluvoxamine in humans is determined by the polymorphic CYP2D6 and also by the CYP1A2 activity. Clin Pharmacol Ther 60:183-190

Carrillo JA, Herraiz AG, Ramos SI et al (2003) Role of the smoking-induced cytochrome P450 (CYP)1A2 and polymorphic CYP2D6 in steady-state concentration of olanzapine. J Clin Psychopharmacol 23:119-127

Chang WH, Lin SK, Lane HY (1997) Clozapine dosages and plasma drug concentrations. J Formos Med Assoc 96:599605

Charlier C, Broly F, Lhermitte M, et al (2003) Polymorphisms in the CYP2D6 gene: association with plasma concentrations of fluoxetine and paroxetine. Ther Drug Monit 25:738-742

Chou WH, Yan FX, de Leon J, et al (2000) Extension of a pilot study: impact from the cytochrome P450 2D6 polymorphism on outcome and costs associated with severe mental illness. J Clin Psychopharmacol 20:246-251

Cozza KL, Armstrong SC, Oesterheld JR (2003) Concise guide to drug interaction principles for medical practice: cytochrome P450s, UGTs, P-Glycoproteins. $2^{\text {nd }}$ edn. American Psychiatric Association, Washington, DC

Crettol S, Déglon JJ, Besson J et al (2005) Methadone enantiomer plasma levels, CYP2B6, CYP2C19, and CYP2C9 genotypes, and response to treatment. Clin Pharmacol Ther 78:593-604

Crettol S, de Leon J, Hiemke C, Eap CB (2014) Pharmacogenomics in psychiatry: from therapeutic drug monitoring to genomic medicine. Clin Pharmacol Ther 95:254-257

Dahl ML (2002) Cytochrome p450 phenotyping/genotyping in patients receiving antipsychotics: useful aid to prescribing? Clin Pharmacokinet 41:453-470

Dahl ML, Bertilsson L, Nordin C (1996) Steady-state plasma levels of nortriptyline and its 10-hydroxy metabolite: relationship to the CYP2D6 genotype. Psychopharmacology 123:315-319 
Dahl-Puustinen ML, Liden A, Alm C et al (1989) Disposition of perphenazine is related to polymorphic debrisoquin hydroxylation in human beings. Clin Pharmacol Ther 46:78-81

Dai D, Tang J, Rose R, Hodgson E et al (2001) Identification of variants of CYP3A4 and characterization of their abilities to metabolize testosterone and chlorpyrifos. J Pharmacol Exp Ther 299:825-831

Dalen P, Dahl ML, Ruiz ML et al (1998) 10-Hydroxylation of nortriptyline in white persons with 0, 1, 2, 3, and 13 functional CYP2D6 genes. Clin Pharmacol Ther 63:444-452

de Leon J (2006) AmpliChip CYP450 test: personalized medicine has arrived in psychiatry. Expert Rev Mol Diagn $6: 277-286$

de Leon J (2007) The crucial role of the therapeutic window in understanding the clinical relevance of the poor versus the ultrarapid metabolizer phenotypes in subjects taking drugs metabolized by CYP2D6 or CYP2C19. J Clin Psychopharmacol 27:241-245

de Leon J (2008) The potential of genotyping. Science 321:769

de Leon J (2009) The future (or lack of future) of personalized prescription in psychiatry. Pharmacol Res 59:81-89

de Leon J (2012) Evidence-based medicine versus personalized medicine: are they enemies? J Clin Psychopharmacol 32:153-164

de Leon J (2014a) False-negative studies may systematically contaminate the literature on the effects of inducers in neuropsychopharmacology. Part I: focus on epilepsy. J Clin Psychopharmacol 34:177-183

de Leon J (2014b) False-negative studies may systematically contaminate the literature on the effects of inducers in neuropsychopharmacology: part II: focus on bipolar disorder. J Clin Psychopharmacol 34:291-296

de Leon J, Armstrong SC, Cozza KL (2006a) Clinical guidelines for psychiatrists for the use of pharmacogenetic testing for CYP450 2D6 and CYP450 2C19. Psychosomatics 47:75-85

de Leon J, Greenlee B, Barber J et al (2009c) Practical guidelines for the use of new generation antipsychotic drugs (except clozapine) in adult individuals with intellectual disabilities. Res Dev Disabil 30:613-669

de Leon J, Sandson NB, Cozza KL (2008) A preliminary attempt to personalize risperidone dosing using drug-drug interactions and genetics: part II. Psychosomatics 49:347-361

de Leon J, Santoro V, D’Arrigo C, Spina E (2012) Interactions between antiepileptics and second-generation antipsychotics. Exp Opin Drug Metab Toxicol 8:311-334

de Leon J, Spina E, Diaz FJ (2013) Clobazam therapeutic drug monitoring: a comprehensive review of the literature with proposals to improve future studies. Ther Drug Monit 35:30-47

de Leon J, Spina E, Diaz FJ (2009b) Pharmacokinetic drug interaction studies must consider pharmacological heterogeneity, use of repeated dosing, and translation into a message understandable to practicing clinicians. J Clin Psychopharmacol 29:201-205

de Leon J, Susce MT, Johnson M et al (2009a) DNA microarray technology in the clinical environment: the AmpliChip CYP450 test for CYP2D6 and CYP2C19 genotyping. CNS Spectr 14:19-34

de Leon J, Susce MT, Murray-Carmichael E (2006b) The AmpliChip CYP450 genotyping test: Integrating a new clinical tool. Mol Diagn Ther 10:135-151

de Leon J, Susce MT, Pan RM et al (2005) The CYP2D6 poor metabolizer phenotype may be associated with risperidone adverse drug reactions and discontinuation. J Clin Psychiatry 66:15-27

de Leon J, Susce MT, Pan RM et al (2007) A study of genetic (CYP2D6 and ABCB1) and environmental (drug inhibitors and inducers) variables that may influence plasma risperidone levels. Pharmacopsychiatry 40:93-102 
de Leon J, Wynn G, Sandson NB (2010) The pharmacokinetics of paliperidone versus risperidone. Psychosomatics $51: 80-88$

Desta Z, Zhao X, Shin JG et al (2002) Clinical significance of the cytochrome P450 2C19 genetic polymorphism. Clin Pharmacokinet 41:913-958

de Vos A, van der Weide J, Loovers HM (2011) Association between CYP2C19*17 and metabolism of amitriptyline, citalopram and clomipramine in Dutch hospitalized patients. Pharmacogenomics J 11:359-367

Drögemöller BI, Wright GE, Niehaus DJ, Emsley R, Warnich L (2013) Next-generation sequencing of pharmacogenes: a critical analysis focusing on schizophrenia treatment. Pharmacogenet Genomics 23:666-674

Drögemöller BI, Wright GE, Warnich L (2014). Considerations for rare variants in drug metabolism genes and the clinical implications. Expert Opin Drug Metab Toxicol 10:873-884.

Eap CB, Bender S, Jaquenoud SE et al (2004) Nonresponse to clozapine and ultrarapid CYP1A2 activity: clinical data and analysis of CYP1A2 gene. J Clin Psychopharmacol 24:214-219

Eap CB, Bondolfi G, Zullino D et al (2001) Concentrations of the enantiomers of fluoxetine and norfluoxetine after multiple doses of fluoxetine in cytochrome P4502D6 poor and extensive metabolizers. J Clin Psychopharmacol 21:330334

Eap CB, Crettol S, Rougier JS et al (2007). Stereoselective block of hERG channel by (S)-methadone and QT interval prolongation in CYP2B6 slow metabolizers. Clin Pharmacol Ther 81:719-728

Eap CB, Lessard E, Baumann P et al (2003) Role of CYP2D6 in the stereoselective disposition of venlafaxine in humans. Pharmacogenetics 13:39-47

Eiermann B, Engel G, Johansson I et al (1997) The involvement of CYP1A2 and CYP3A4 in the metabolism of clozapine. Br J Clin Pharmacol 44:439-446

Ereshefsky L (1996) Pharmacokinetics and drug interactions: update for new antipsychotics. J Clin Psychiatry 57 Suppl $11: 12-25$

Fang J, McKay G, Song J, et al (2001) In vitro characterization of the metabolism of haloperidol using recombinant cytochrome p450 enzymes and human liver micro-somes. Drug Metab Dispos 29:1638-1643

Fric M, Pfuhlmann B, Laux G et al (2008) The influence of smoking on the serum level of duloxetine. Pharmacopsychiatry 41:151-155

Fudio S, Borobia AM, Pinana E et al (2010) Evaluation of the influence of sex and CYP2C19 and CYP2D6 polymorphisms in the disposition of citalopram. Eur J Pharmacol 626:200-204

Fukuda T, Nishida Y, Zhou Q et al (2000) The impact of the CYP2D6 and CYP2C19 genotypes on venlafaxine pharmacokinetics in a Japanese population. Eur J Clin Pharmacol 56:175-180

Gaohua L, Abduljalil K, Jamei M et al (2012) A pregnancy physiologically based pharmacokinetic (p-PBPK) model for disposition of drugs metabolized by CYP1A2, CYP2D6 and CYP3A4. Br J Clin Pharmacol 74:873-885

Gerstenberg G, Aoshima T, Fukasawa T et al. (2003) Effects of the CYP 2D6 genotype and cigarette smoking on the steady-state plasma concentrations of fluvoxamine and its major metabolite fluvoxamino acid in Japanese depressed patients. Ther Drug Monit 25:463-468

Grossman I, Sullivan PF, Walley N et al (2008) Genetic determinants of variable metabolism have little impact on the clinical use of leading antipsychotics in the CATIE study. Genet Med 10:720-729

Hägg S, Spigset O, Lakso HA, Dahlqvist R (2001) Olanzapine disposition in humans is unrelated to CYP1A2 and CYP2D6 phenotypes. Eur J Clin Pharmacol 57:493-497

Hesse LM, Venkatakrishnan K, Court MH et al (2000) CYP2B6 mediates the in vitro hydroxylation of bupropion: potential drug interactions with other antidepressants. Drug Metab Dispos 28:1176-1183 
Hicks JK, Swen JJ, Thorn CF et al (2013) Clinical Pharmacogenetics Implementation Consortium guideline for CYP2D6 and CYP2C19 genotypes and dosing of tricyclic antidepressants. Clin Pharmacol Ther 93:402-408

Hiemke C, Baumann P, Bergemann N et al (2011) AGNP consensus guidelines for therapeutic drug monitoring in psychiatry: update 2011 Pharmacopsychiatry 44:195-235

Hiemke C, Pfuhlmann B (2012) Interactions and monitoring of antipsychotic drugs. Handb Exp Pharmacol 212:241265

Hiemke C, Shams M (2013) Phenotyping and genotyping of drug metabolism to guide pharmacotherapy in psychiatry. Curr Drug Deliv 10:46-53

Ingelman-Sundberg M, Sim SC, Gomez A, Rodriguez-Antona C (2007) Influence of cytochrome P450 polymorphism on drug therapies: pharmacogenetic, pharmacoepigenetic and clinical aspects. Pharmacol Ther 116:496-526

Inomata S, Nagashima A, Itagaki F et al (2005) CYP2C19 genotype affects diazepam pharmacokinetics and emergence from general anesthesia. Clin Pharmacol Ther 78:647-655

Jan MW, ZumBrunnen TL, Kazmi YR et al (2002) Pharmacokinetics of fluvoxamine in relation to CYP2C19 phenotype and genotype. Drug Metabol Drug Interact 19:1-11

Jaquenoud Sirot E, Knezevic B, Morena GP (2009) ABCB1 and cytochrome P450 polymorphisms: clinical pharmacogenetics of clozapine. J Clin Psychopharmacol 29:319-326

Jerling M, Dahl ML, Aberg-Wistedt A et al (1996) The CYP2D6 genotype predicts the oral clearance of the neuroleptic agents perphenazine and zuclopenthixol. Clin Pharmacol Ther 59:423-428

Jiang ZP, Shu Y, Chen XP et al (2002) The role of CYP2C19 in amitriptyline N-demethylation in Chinese subjects. Eur J Clin Pharmacol 58:109-113

Jin Y, Pollock BG, Frank E, et al (2010) Effect of age, weight, and CYP2C19 genotype on escitalopram exposure. J Clin Pharmacol 50:62-72

Johnson M, Markham-Abedi C, Susce MT et al (2006) A poor metabolizer for cytochromes P450 2D6 and 2C19: a case report on antidepressant treatment. CNS Spectr 11:757-760

Katoh Y, Uchida S, Kawai M, et al (2010) Effects of cigarette smoking and cytochrome P450 2D6 genotype on fluvoxamine concentration in plasma of Japanese patients. Bio Pharm Bull 33:285-288

Kawanishi C, Lundgren S, Agren H, Bertilsson L (2004). Increased incidence of CYP2D6 gene duplication in patients with persistent mood disorders: ultrarapid metabolism of antidepressants as a cause of nonresponse.A pilot study. Eur $\mathbf{J}$ Clin Pharmacol 59:803-807

Kirchheiner J, Brosen K, Dahl ML et al (2001) CYP2D6 and CYP2C19 genotype-based dose recommendations for antidepressants: a first step towards subpopulation specific dosages. Acta Psychiatr Scand 104:173-192

Kirchheiner J, Klein C, Meineke I et al (2003) Bupropion and 4-OHbupropion pharmacokinetics in relation to genetic polymorphisms in CYP2B6. Pharmacogenetics 13:619-626

Kirchheiner J, Nickchen K, Bauer M et al (2004) Pharmacogenetics of antidepressants and antipsychotics: the contribution of allelic variations to the phenotype of drug response. Mol Psychiatry 9:442-473

Kohnke MD, Griese EU, Stosser D et al (2002) Cytochrome P4502D6 deficiency and its clinical relevance in a patient treated with risperidone. Pharmacopsychiatry 35:116-118

Kootstra-Ros JE, Smallegoor W, van der WJ (2005) The cytochrome P450 CYP1A2 genetic polymorphisms *1F and *1D do not affect clozapine clearance in a group of schizophrenic patients. Ann Clin Biochem 42:216-219

Koyama E, Tanaka T, Chiba K et al (1996) Steady-state plasma concentrations of imipramine and desipramine in relation to S-mephenytoin 4'-hydroxylation status in Japanese depressive patients. J Clin Psychopharmacol 16:286-293 
Laika B, Leucht S, Heres S et al (2010) Pharmacogenetics and olanzapine treatment: CYP1A2*1F and serotonergic polymorphisms influence therapeutic outcome. Pharmacogenomics J 10: 20-29.

Lantz RJ, Gillespie TA, Rash TJ et al (2003) Metabolism, excretion, and pharmacokinetics of duloxetine in healthy human subjects. Drug Metab Dispos 31:1142-1150

Lind AB, Reis M, Bengtsson F et al (2009) Steady-state concentrations of mirtazapine, N-desmethylmirtazapine, 8hydroxymirtazapine and their enantiomers in relation to cytochrome P450 2D6 genotype, age and smoking behaviour. Clin Pharmacokinet 48:63-70

Linnet K (2002) Glucuronidation of olanzapine by cDNA-expressed human UDP-glucuronosyltransferases and human liver microsomes. Hum Psychopharmacol 17:233-238

Linnet K, Wiborg O (1996a) Influence of Cyp2D6 genetic polymorphism on ratios of steady-state serum concentration to dose of the neuroleptic zuclopenthixol. Ther Drug Monit 18:629-634

Linnet K, Wiborg O (1996b) Steady-state serum concentrations of the neuroleptic perphenazine in relation to CYP2D6 genetic polymorphism. Clin Pharmacol Ther 60:41-47

Liu ZQ, Cheng ZN, Huang SL et al (2001) Effect of the CYP2C19 oxidation polymorphism on fluoxetine metabolism in Chinese healthy subjects. Br J Clin Pharmacol 52:96-99

Llerena A, Alm C, Dahl ML et al (1992) Haloperidol disposition is dependent on debrisoquine hydroxylation phenotype. Ther. Drug Monit. 14:92-97

Llerena A, Berecz R, Dorado P, de la Rubia A (2004a) QTc interval, CYP2D6 and CYP2C9 genotypes and risperidone plasma concentrations. J Psychopharmacol 18:189-193

Llerena A, Dorado P, Berecz R et al (2004b) Effect of CYP2D6 and CYP2C9 genotypes on fluoxetine and norfluoxetine plasma concentrations during steady-state conditions. Eur J Clin Pharmacol 59:869-873

Martis S. Mey H, Vijzelar R et al (2013) Multi-ethnic distribution of clinically relevant CYP2C genotypes and haplotypes. Pharmacogenomics J 13:558-566

Matchar DB, Thakur ME, Grossman I et al (2006) Testing for cytochrome P450 polymorphisms in adults with nonpsychotic depression treated with selective serotonin reuptake inhibitors (SSRIs). Evidence Report/Technology Assessment No. 146. (Prepared by the Duke Evidence-based Practice Center under Contract No. 290-02-0025.) Agency for Healthcare Research and Quality Publication No. 07-E002. Rockville, MD http://archive.ahrq.gov/downloads/pub/evidence/pdf/cyp450/cyp450.pdf Accessed 23 June 2014

McAllister-Williams RH, Baldwin DS, Haddad PM et al (2010) The use of antidepressants in clinical practice: focus on agomelatine. Hum Psychopharmacol 25:95-102

Melkersson KI, Scordo MG, Gunes A, Dahl ML (2007) Impact of CYP1A2 and CYP2D6 polymorphisms on drug metabolism and on insulin and lipid elevations and insu-lin resistance in clozapine-treated patients. J Clin Psychiatry 68:697-704

Meyer UA (2004) Pharmacogenetics - five decades of therapeutic lessons from genetic diversity Nat Rev 5:869-876

Mihara K, Suzuki A, Kondo T et al (1999) Effects of the CYP2D6*10 allele on the steady-state plasma concentrations of haloperidol and reduced haloperidol in Japanese patients with schizophrenia. Clin Pharmacol Ther 65:291-294

Mihara K, Kondo T, Suzuki A et al (2001) Effects of genetic polymorphism of CYP1A2 inducibility on the steady-state plasma concentrations of trazodone and its active metabolite m-chlorophenylpiperazine in depressed Japanese patients. Pharmacol Toxicol 88:267-270

Morinobu S, Tanaka T, Kawakatsu S et al (1997) Effects of genetic defects in the CYP2C19 gene on the Ndemethylation of imipramine, and clinical outcome of imipramine therapy. Psychiatry Clin Neurosi 51:253-257

Murayama N, Soyama A, Saito Y et al (2004) Six novel nonsynonymous CYP1A2 gene polymorphisms: catalytic activities of the naturally occurring variant enzymes. J Pharmacol Exp Ther 308:300-306 
Nelson DR (2009) The cytochrome p450 homepage. Hum Genomics 4:59-65

Nichols AI, Lobello K, Guico-Pabia CJ et al (2009) Venlafaxine metabolism as a marker of cytochrome P450 enzyme 2D6 metabolizer status. J Clin Psychopharmacol 29:383-386

Noehr-Jensen L, Zwisler ST, Larsen F et al (2009) Impact of CYP2C19 phenotypes on escitalopram metabolism and an evaluation of pupillometry as a serotonergic biomarker. Eur J Clin Pharmacol 65:887-894

Nozawa M, Ohnuma T, Matsubara Y et al (2008) The relationship between the response of clinical symptoms and plasma olanzapine concentration, based on pharmacogenetics: Juntendo University Schizophrenia Projects (JUSP). Ther Drug Monit 30(1):35-40

Ostad Haji E, Hiemke C, Pfuhlmann B (2012) Therapeutic drug monitoring for antidepressant drug treatment. Curr Pharm Des 18:5818-5827

Otsuka America Pharmaceutical,Inc. (2013) Abilify maintena-aripiprazole. Highlights of prescribing information. Tokyo, Japan: Otsuka Pharmaceutical Co., Ltd. February 2013. http://dailymed.nlm.nih.gov/dailymed/lookup.cfm?setid=ee49f3b1-1650-47ff-9fb1-ea53fe0b92b6\#nlm34068-7

Accessed 28 June 2014

Ozdemir V, Bertilsson L, Miura J, et al (2007) CYP2D6 genotype in relation to perphenazine concentration and pituitary pharmacodynamic tissue sensitivity in Asians: CYP2D6-serotonin-dopamine crosstalk revisited. Pharmacogenet Genomics 17:339-347

Ozdemir V, Kalow W, Okey AB et al (2001) Treatment-resistance to clozapine in association with ultrarapid CYP1A2 activity and the $\mathrm{C}_{-}>\mathrm{A}$ polymorphism in intron 1 of the CYP1A2 gene: effect of grapefruit juice and low-dose fluvoxamine. J Clin Psychopharmacol 21:603-607

Ozdemir V, Kalow W, Tang BK et al (2000) Evaluation of the genetic component of variability in CYP3A4 activity: a repeated drug administration method. Pharmacogenetics 10:373-388

Parker G, Fink M, Shorter E, Taylor MA et al (2010) Issues for DSM-5: whither melancholia? The case for its classification as a distinct mood disorder. Am J Psychiatry 167:745-747

Pavanello S, Pulliero A, Lupi S, et al (2005) Influence of the genetic polymorphism in the 5'-noncoding region of the CYP1A2 gene on CYP1A2 phenotype and urinary mutagenicity in smokers. Mutat Res 587:59-66

Porcelli S, Fabbri C, Spina E et al (2011) Genetic polymorphisms of cytochrome P450 enzymes and antidepressant metabolism. Exp Opin Drug Metab Toxicol 7:1101-1115

Preskorn SH (1989) Tricyclic antidepressants: the whys and hows of therapeutic drug monitoring. J Clin Psychiatry 50 Suppl:34-42; discussion 43-46

Preskorn SH, Kane CP, Lobello K et al (2013) Cytochrome P450 2D6 phenoconversion is common in patients being treated for depression: implications for personalized medicine. J Clin Psychiatry 74:614-621

Puranik YG, Birnbaum AK, Marino SE et al (2013) Association of carbamazepine major metabolism and transport pathway gene polymorphisms and pharmacokinetics in patients with epilepsy. Pharmacogenomics 14:35-45

Rau T, Wohlleben G, Wuttke H et al (2004) CYP2D6 genotype: impact on adverse effects and nonresponse during treatment with antidepressants_a pilot study. Clin Pharmacol Ther 75:386-393

Ravyn D, Ravyn V, Lowney R, Nasrallah HA (2013) CYP450 pharmacogenetic treatment strategies for antipsychotics: a review of the evidence. Schizophr Res 149:1-14

Rendic S (2002) Summary of information on human CYP ezymes: human P450 metabolism data. Drug Metab Rev $34: 83-448$

Ring BJ, Catlow J, Lindsay TJ et al (1996) Identification of the human cytochromes P450 responsible for the in vitro formation of the major oxidative metabolites of the antipsychotic agent olanzapine. J Pharmacol Exp Ther 276:658-666 
Rogers HL, Bhattaram A, Zineh I et al (2012) CYP2D6 genotype information to guide pimozide treatment in adult and pediatric patients: basis for the U.S. Food and Drug Administration's new dosing recommendations. J Clin Psychiatry 73:1187-1190

Roh HK, Kim CE, Chung WG et al (2001) Risperidone metabolism in relation to CYP2D6*10 allele in Korean schizophrenic patients. Eur J Clin Pharmacol 57:671-675

Rudberg I, Mohebi B, Hermann M et al (2008) Impact of the ultrarapid CYP2C19*17 allele on serum concentration of escitalopram in psychiatric patients. Clin Pharmacol Ther 83:322-327

Sachse C, Brockmoller J, Bauer S, Roots I (1999) Functional significance of a C- > A polymorphism in intron 1 of the cytochrome P450 CYP1A2 gene tested with caffeine. Br J Clin Pharmacol 47:445-449

Samer CF, Lorenzini KI, Rollason V et al (2013) Applications of CYP450 testing in the clinical setting. Mol Diagn Ther 17:165-184

Sawamura K, Suzuki Y, Someya T (2004) Effects of dosage and CYP2D6-mutated allele on plasma concentration of paroxetine. Eur J Clin Pharmacol 60:553-557

Schenk PW, van Vliet M, Mathot RA et al (2010) The CYP2C19*17 genotype is associated with lower imipramine plasma concentrations in a large group of depressed patients. Pharmacogenomics J 10:3229-3225

Scordo MG, Spina E (2002) Cytochrome P450 polymorphism and response to antipsychotic therapy. Pharmacogenomics 3:201-218

Scordo MG, Spina E, Dahl ML et al (2005) Influence of CYP2C9, 2C19 and 2D6 genetic polymorphisms on the steady state plasma concentrations of the enantiomers of fluoxetine and norfluoxetine. Basic Clin Pharmacol Toxicol 97:296301

Scordo MG, Spina E, Facciola G et al (1999) Cytochrome P450 2D6 genotype and steady state plasma levels of risperidone and 9-hydroxyrisperidone. Psychopharmacology 147:300-305

Scott SA, Sangkuhl K, Gardner EE et al (2011) Clinical Pharmacogenetics Implementation Consortium guidelines for cytochrome P450-2C19 (CYP2C19) genotype and clopidogrel therapy. Clin Pharmacol Ther 90:328-332

Sheffield LJ, Phillimore HE (2009) Clinical use of pharmacogenomic tests in 2009. Clin Biochem Rev 30:55-65

Shen H, He MM, Liu H et al (2007) Comparative metabolic capabilities and inhibitory profiles of CYP2D6.1, CYP2D6.10, and CYP2D6.17. Drug Metab Dispos 35:1292-1300

Shimada, T, Yamazaki H, Mimura M et al (1994) Interindividual variations in human liver cytochrome P450 enzymes involved in the oxidation of drugs, carcinogens and toxic chemicals: studies with liver microsomes of 30 Japanese and 30 Caucasians. J Pharmacol Exp Ther 270:414-423

Shimoda K, Someya T, Yokono A et al (2002) The impact of CYP2C19 and CYP2D6 genotypes on metabolism of amitriptyline in Japanese psychiatric patients. J Clin Psychopharmacol 22:371-378

Shirley KL, Hon YY, Penzak SR (2003) Correlation of cytochrome P450 (CYP) 1A2 activity using caffeine phenotyping and olanzapine disposition in healthy volunteers. Neuropsychopharmacology 28:961-966

Sistonen J1, Sajantila A, Lao O et al (2007) CYP2D6 worldwide genetic variation shows high frequency of altered activity variants and no continental structure. Pharmacogenet Genomics. 17:93-101

Söderberg MM, Dahl ML (2013) Pharmacogenetics of olanzapine metabolism. Pharmacogenomics 14:1319-1336

Someya T, Shimoda K, Suzuki Y (2003) Effect of CYP2D6 genotypes on the metabolism of haloperidol in a Japanese psychiatric population. Neuropsychopharmacology 28:1501-1505

Spina E, de Leon J (2007) Metabolic drug interactions with newer antipsychotics: a comparative review. Basic Clin Pharmacol Toxicol 100:4-22 
Spina E, de Leon J (2014) Clinically relevant interactions between newer antidepressants and second-generation antipsychotics. Exp Opin Drug Metab Toxicol 10:721-746

Spina E, Gitto C, Avenoso A et al (1997) Relationship between plasma desipramine levels, CYP2D6 phenotype and clinical response to desipramine: a prospective study. Eur J Clin Pharmacol 51:395-398

Spina E, Santoro V, D’Arrigo C (2008) Clinically relevant pharmacokinetic drug interactions with second-generation antidepressants: an update. Clin Ther 30:1206-1227

Steimer W, Zopf K, Von Amelunxen S et al (2004) Allele-specific change of concentration and functional gene dose for the prediction of steady-state serum concentrations of amitriptyline and nortriptyline in CYP2C19 and CYP2D6 extensive and intermediate metabolizers. Clin Chem 50:1623-1633

Stormer E, von Moltke LL, Shader RI et al (2000) Metabolism of the antidepressant mirtazapine in vitro: contribution of cytochromes P-450 1A2, 2D6, and 3A4. Drug Metab Dispos 28:1168-1175

Strom CM, Goos D, Crossley B et al (2012) Testing for variants in CYP2C19: population frequencies and testing experience in a clinical laboratory. Genet Med 14:95-100

Suzuki A, Otani K, Mihara K et al (1997) Effects of the CYP2D6 genotype on the steady-state plasma concentrations of haloperidol and reduced haloperidol in Japanese schizophrenic patients. Pharmacogenetics 7:415-418

Suzuki Y, Sugai T, Fukui N et al (2011) CYP2D6 genotype and smoking influence fluvoxamine steady-state concentration in Japanese psychiatric patients: lessons for genotype-phenotype association study design in translational pharmacogenetics. J Psychopharmacol 25:908-914

Swen JJ, Nijenhuis M, de Boer A et al (2011) Pharmacogenetics: from bench to byte-an update of guidelines. Clin Pharmacol Ther 89:662-673

The Human Cytochrome P450 (CYP) Allele Nomenclature Committee (2014) The human Cytochrome P450 (CYP) allele nomenclature database. http://www.cypalleles.ki.se/ Accessed August 112014

Thieme D, Rolf B, Sachs H et al (2008) Correlation of inter-individual variations of amitriptyline metabolism examined in hairs with CYP2C19 and CYP2D6 polymorphisms. Int J Legal Med 122:149-155

Tiwari AK, Souza RP, Müller DJ (2009) Pharmacogenetics of anxiolytic drugs. J Neural Transm 116:667-677

Tod M, Goutelle S, Clavel-Grabit F et al (2011) Quantitative prediction of cytochrome P450 (CYP) 2D6-mediated drug interactions. ClinPharmacokinet 50:519-530

Tsai MH, Lin KM, Hsiao MC et al (2010) Genetic polymorphisms of cytochrome P450 enzymes influence metabolism of the antidepressant escitalopram and treatment response. Pharmacogenomics 11:537-546

Ueda M, Hirokane G, Morita S et al (2006) The impact of CYP2D6 genotypes on the plasma concentration of paroxetine in Japanese psychiatric patients. Prog Neuropsychopharmacol Biol Psychiatry 30:486-491

van der Weide J, van Baalen-Benedek EH, Kootstra-Ros JE (2005) Metabolic ratios of psychotropics as indication of cytochrome P450 2D6/2C19 genotype. Ther Drug Monit 27:478-483

van der Weide K, van der Weide J (2014) The influence of the CYP3A4*22 polymorphism on serum concentration of quetiapine in psychiatric patients. J Clin Psychopharmacol 34:256-260

Veefkind AH, Haffmans PM, Hoencamp E (2000) Venlafaxine serum levels and CYP2D6 genotype. Ther Drug Monit 22:202-208

Wang JH, Liu ZQ, Wang W et al (2001) Pharmacokinetics of sertraline in relation to genetic polymorphism of CYP2C19. Clin Pharmacol Ther 70:42-47

Watanabe J, Suzuki Y, Fukui N et al (2008) Dose-dependent effect of the CYP2D6 genotype on the steady-state fluvoxamine concentration. Ther Drug Monit 30:705-708 
Whyte EM, Romkes M, Mulsant BH et al (2006) CYP2D6 genotype and venlafaxine-XR concentrations in depressed elderly. Int J Geriatr Psychiatry 21:542-549

Wong WB, Carlson JJ, Thariani R, et al (2010) Cost effectiveness of pharmacogenomics: a critical and systematic review. Pharmacoeconomics 28:1001-1013

Yin OQ, Wing YK, Cheung Y et al (2006) Phenotype-genotype relationship and clinical effects of citalopram in Chinese patients. J Clin Psychopharmacol 26:367-372

Yokono A, Morita S, Someya T et al (2001) The effect of CYP2C19 and CYP2D6 genotypes on the metabolism of clomipramine in Japanese psychiatric patients. J Clin Psychopharmacol 21:549-555

Yu BN, Chen GL, He N et al (2003) Pharmacokinetics of citalopram in relation to genetic polymorphism of CYP2C19. Drug Metab Dispos 31:1255-1259

Yu KS, Yim DS, Cho JY et al (2001). Effect of omeprazole on the pharmacokinetics of moclobemide according to the genetic polymorphism of CYP2C19. Clin Pharmacol Ther 69:266-273

Zanger UM, Schwab M (2013) Cytochrome P450 enzymes in drug metabolism: Regulation of gene expression, enzyme activities, and impact of genetic variation. Pharmacol Ther 138:103-141

Zhou SF (2009a) Polymorphism of human cytochrome P450 2 D6 and its clinical significance. Part I. Clin Pharmacokinet 48:689-723

Zhou SF (2009b) Polymorphism of human cytochrome P450 2D6 and its clinical significance. Part II. Clin Pharmacokinet 48:761-804

Zhou SF, Liu JP, Chowbay B (2009) Polymorphism of human cytochrome P450 enzymes and its clinical impact. Drug Metab Rev 41:89-295

Zhou SF, Zhou ZW, Huang M (2010) Polymorphisms of human cytochrome P450 2 C9 and the functional relevance. Toxicology 278:165-188 

Table 1. Cytochrome P450 isoforms and psychotropic drugs as substrates, inhibitors or inducers

\begin{tabular}{|c|c|c|c|}
\hline \multirow[t]{2}{*}{ CYP isoform } & \multicolumn{3}{|l|}{ Psychotropic drugs } \\
\hline & Substrates & Inhibitors $^{\mathbf{a}}$ & Inducers $^{\mathbf{a}}$ \\
\hline CYP1A2 & $\begin{array}{l}\text { Antidepressants: tricyclics (demethylation), fluvoxamine, trazodone, } \\
\text { duloxetine, mirtazapine, agomelatine } \\
\text { Antipsychotics: haloperidol, thioridazine, clozapine, olanzapine, asenapine }\end{array}$ & Fluvoxamine (potent) & Carbamazepine \\
\hline CYP2B6 & $\begin{array}{l}\text { Antidepressants: bupropion } \\
\text { Opioids: methadone }\end{array}$ & & Carbamazepine \\
\hline CYP2C9 & $\begin{array}{l}\text { Antidepressants: fluoxetine } \\
\text { Mood stabilizers: valproic acid } \\
\text { Hypnotics: zolpidem, zopiclone }\end{array}$ & $\begin{array}{l}\text { Fluoxetine (moderate) } \\
\text { Fluvoxamine (moderate) } \\
\text { Valproic acid (weak) }\end{array}$ & Carbamazepine \\
\hline CYP2C19 & $\begin{array}{l}\text { Antidepressants: tricyclics (demethylation), sertraline, citalopram, } \\
\text { escitalopram, moclobemide } \\
\text { Anxiolytics: diazepam, clobazam }\end{array}$ & $\begin{array}{l}\text { Fluvoxamine (potent) } \\
\text { Fluoxetine (moderate) }\end{array}$ & Carbamazepine \\
\hline CYP2D6 & $\begin{array}{l}\text { Antidepressants: tricyclics (hydroxylation), fluoxetine, fluvoxamine, } \\
\text { paroxetine, citalopram, escitalopram, venlafaxine, mirtazapine, duloxetine, } \\
\text { vortioxetine } \\
\text { Antipsychotics: haloperidol, chlorpromazine, fluphenazine, perphenazine, } \\
\text { thioridazine, zuclopenthixol, pimozide, clozapine, olanzapine, risperidone, } \\
\text { iloperidone, aripiprazole } \\
\text { Drugs for attention-deficit/hyperactivity disorder: atomoxetine }\end{array}$ & $\begin{array}{l}\text { Fluoxetine (potent) } \\
\text { Paroxetine (potent) } \\
\text { Sertraline (moderate) } \\
\text { Duloxetine (moderate) } \\
\text { Bupropion (moderate) } \\
\text { Thioridazine (potent) } \\
\text { Perphenazine (potent) } \\
\text { Asenapine (weak) }\end{array}$ & \\
\hline CYP3A4 & $\begin{array}{l}\text { Antidepressants: tricyclics (demethylation), sertraline, citalopram, } \\
\text { escitalopram, venlafaxine, mirtazapine, trazodone, reboxetine, vilazodone } \\
\text { Antipsychotics: haloperidol, thioridazine, pimozide, clozapine, quetiapine, } \\
\text { risperidone, iloperidone, aripiprazole, ziprasidone, lurasidone } \\
\text { Anxiolytics: alprazolam, midazolam, triazolam } \\
\text { Mood stabilizers: carbamazepine } \\
\text { Opioids: methadone }\end{array}$ & $\begin{array}{l}\text { Fluoxetine (moderate) } \\
\text { Fluvoxamine (moderate) }\end{array}$ & Carbamazepine \\
\hline
\end{tabular}

anducers and inhibitors are restricted to psychotropic drugs. 

Table 2. Pharmacogenetic guidelines using CYP2C19 and CYP2D6 for dosing psychiatric drugs

Aripiprazole, haloperidol, risperidone and zuclopenthixol

CYP2D6 PMs: $\downarrow$ dose by 50\% or select another antipsychotic (Swen et al. 2011).

CYP2D6 UMs: alert to diminished serum concentrations or prescribe another antipsychotic (Swen et al. 2011).

\section{Atomoxetine}

CYP2D6 UMs: be alert to reduced efficacy or select alternative drugs (Swen et al. 2011).

\section{Long-acting intramuscular aripiprazole ${ }^{\mathrm{a}}$}

CYP2D6 PMs: $\downarrow$ dose to $75 \%$ a (Otsuka America Pharmaceutical, Inc. 2013)

\section{Pimozide}

If prescribing $>4 \mathrm{mg}$ /day in adults, CYP2D6 genotyping is required by the US prescribing information because 4 mg/day is the maximum recommended dose in CYP2D6 PMs (Rogers et al. 2012).

\section{TCAs}

CYP2D6 PMs: avoid TCAs or $\downarrow$ dose by $50 \%$ and use TDM to adjust dosing (Hicks et al. 2014).

CYP2D6 UMs: avoid TCAs (Hicks et al. 2014).

CYP2C19 PMs and amitriptyline ${ }^{\mathrm{b}}: \downarrow$ dose by 50\% and use TDM to adjust dosing (Hicks et al. 2014).

CYP2C19 UMs and amitriptyline ${ }^{\text {b: }}$ select another antidepressant not metabolized by CYP2C19 (Hicks et al. 2014).

\section{Venlafaxine}

CYP2D6 PMs: select another antidepressant or use venlafaxine TDM (Swen et al. 2011).

CYP2D6 UMs: increase dose by a factor of 1.5 (Swen et al. 2011).

CYP: cytochrome P450; PM: poor metabolizer; TCA: tricyclic antidepressant; TDM: therapeutic drug monitoring: UM: ultrarapid metabolizer.

${ }^{\mathrm{a}} \downarrow$ dose by 50\% in CYP2D6 PMs taking CYP3A4 inhibitors.

${ }^{\mathrm{b}}$ This recommendation probably applies to imipramine and clomipramine. 
Table 3. Explaining pharmacokinetic concepts to personalize dosing: linear kinetics and concentration/dose (C/D) ratio

\section{Linear (and non-linear) kinetics}

-Linear kinetics: In typical doses, most antipsychotics and many antidepressants have a linear relationship between typical doses and their serum concentrations. This means that the relationship between concentration doses is stable; it does not change with different doses or concentrations, and the C/D ratio is constant.

-Non-linear kinetics: Some psychiatric drugs have non-linear kinetics. Paroxetine and fluoxetine, that inhibit their own metabolism. Carbamazepine, which induces its own metabolism, has non-linear kinetics during the time that it induces its own metabolism. Drugs with non-linear kinetics have a variable C/D ratio that changes at different doses or different concentrations. It is more difficult to predict the correct doses in drugs with non-linear kinetics.

\section{C/D ratio}

The $\mathrm{C} / \mathrm{D}$ ratio measures the ability to eliminate the drug. It can be influenced by genetic, environmental and personal factors. Inducers $\downarrow$ the $\mathrm{C} / \mathrm{D}$ ratio and inhibitors $\uparrow$ the $\mathrm{C} / \mathrm{D}$ ratio. When a drug is eliminated as active compounds in the urine, geriatric age or renal impairment can $\uparrow$ the drug C/D ratio. Hepatic impairment can also $\uparrow$ the drug $\mathrm{C} / \mathrm{D}$ ratio of some drugs. Each drug has its own normal C/D ratio that is influenced by the percentage of absorption (bioavailability) and elimination from the body (drug clearance). 


\section{Clozapine versus norclozapine}

-Norclozapine has no antipsychotic activity. Therefore, it can be ignored when calculating C/D ratios by clinicians focused on clozapine efficacy.

-Norclozapine can contribute to ADRs, particularly antimuscarinic ADRs. Thus, adding clozapine and norclozapine to calculate a total C/D ratio provides a more accurate measure of the ability to eliminate clozapine from the body (clozapine clearance) and is better for establishing the risk of some ADRs such as antimuscarinic ADRs.

\section{Clozapine pharmacokinetics}

-CYP1A2 has been considered the main metabolic pathway for clozapine. CYP2C19 may be more important than previously thought. CYP2D6, CYP3A4 and UGTs may also be minor pathways. Renal elimination may also have a minor contribution. $\uparrow$ weight is associated with $\downarrow$ clozapine elimination, probably due to fat storage.

Genetic, environmental or personal factors leading to the need for high or low clozapine doses 1) Subjects requiring higher doses:

-Individuals with extremely high CYP1A2 activity are probably very rare $(<1 \%)$.

-Smokers need higher doses. Smoking $\downarrow$ C/D ratio by a factor of approximately 1.5. Therefore, smoking patients need $\uparrow$ in dose (approximately 1.5 times higher) to reach therapeutic clozapine concentrations.

-Inducers such as rifampin, phenytoin, and phenobarbital $\downarrow \mathrm{C} / \mathrm{D}$ ratio by a factor of approximately 1.5.Therefore, patients taking inducers need $\uparrow$ in dose (approximately 1.5 times higher) to reach therapeutic clozapine concentrations. -Mild inducers of clozapine may include valproate, charbroiled food, roasted coffee, omeprazole and cruciferous vegetables (including broccoli). Adding these mild inducers does not usually require changing clozapine dose.

2) Subjects requiring lower doses:

-Individuals with extremely low CYP1A2 activity are probably rare $(<1 \%)$. CYP2C19 PMs may have half the ability to metabolize clozapine, ${ }^{\mathrm{a}}$ along with C/D ratios twice as high as CYP2C19 EMs.

-Fluvoxamine is a very powerful inhibitor. On average, it $\uparrow$ the $\mathrm{C} / \mathrm{D}$ ratio by 3 times, which requires $\downarrow$ clozapine doses to $1 / 3$. Published cases of $\uparrow$ of 5-10 times in C/D ratios exist. Do not prescribe fluvoxamine without clozapine TDM. -Ciprofloxacin (and some similar antibiotics) and caffeine in high doses are clinically relevant inhibitors and may require $\downarrow$ clozapine dose by half. Similarly, major inflammations or infections (pneumonias, upper respiratory infections with fever, pyelonephritis or appendicitis) may decrease clozapine metabolism and may require $\downarrow$ clozapine dose by half. Oral contraceptives and estrogen elevations during pregnancy can inhibit clozapine metabolism. -Fluoxetine and paroxetine are mild inhibitors of clozapine metabolism ( dose changes are not usually required). -Females have lower capacity to metabolize clozapine, probably due to the presence of estrogens.

-Patients with renal or hepatic insufficiency need lower clozapine doses, but there are no studies to guide dosing. -With advanced age, particularly after the age of 65 years, there is a progressive diminution of the ability to eliminate clozapine. The $\uparrow \mathrm{C} / \mathrm{D}$ ratio associated with aging is small.

\section{Relating C/D ratios and therapeutic $\operatorname{doses}^{\mathrm{b}}$ with examples representing average patients}

1) A subject requires $900 \mathrm{mg} / \mathrm{day}$ to get $350 \mathrm{ng} / \mathrm{ml}$ of clozapine concentration. The $\mathrm{C} / \mathrm{D}$ ratio $=0.4(350 / 900=0.4)$.

a) The last author has seen a few patients with C/D ratios around 0.4, male Caucasian smokers taking potent inducers such as phenytoin.

2) A subject requires $600 \mathrm{mg} /$ day to get $350 \mathrm{ng} / \mathrm{ml}$ of clozapine concentration. The C/D ratio=0.6 (350/600=0.6).

a) Male Caucasian smokers typically have C/D ratios around 0.6.

3) A subject requires $300 \mathrm{mg} /$ day to get $350 \mathrm{ng} / \mathrm{ml}$ of clozapine concentration. The $\mathrm{C} / \mathrm{D}$ ratio=1.2 (350/300=1.2).

a) Female Caucasian non-smokers typically have C/D ratios around 1.2.

b) Male Caucasian smokers taking a clinically-relevant inhibitor may have C/D ratios around 1.2.

c) The review of the literature suggests that male East Asian smokers may have C/D ratios around 1.2.

d) Although not well studied, CYP2C19 PM smokers may have C/D ratios around 1.2.

4) A subject requires $150 \mathrm{mg} /$ day to get $350 \mathrm{ng} / \mathrm{ml}$ of clozapine concentration. The C/D ratio=2.3 $(350 / 150=2)$.

a) Female Caucasian non-smokers taking a clinically-relevant inhibitor may have C/D ratios around 2.3.

b) The review of the literature suggests that female East Asian non-smokers may have C/D ratios around 2.3.

c) Although not well studied, CYP2C19 PM non-smokers may have C/D ratios around 2.3.

ADR: adverse drug reaction; C/D ratio: concentration/dose ratio; CYP: cytochrome P450; EM: extensive metabolizer; PM: poor metabolizer; TDM: therapeutic drug monitoring; UGT: uridine diphosphate glucuronosyltransferase. Jaquenoud Sirot et al. 2009.

${ }^{\mathrm{b}}$ There is general agreement in the literature that serum clozapine concentrations exceeding $350 \mathrm{ng} / \mathrm{ml}$ are therapeutic. This table describes therapeutic doses as providing a serum clozapine concentration $>350 \mathrm{ng} / \mathrm{ml}$. 
Table 5. Current approximations for initial clozapine dosing and subsequent use of clozapine TDM for average adults

\section{FIRST WEEK}

-Typical ${ }^{\mathrm{a}}$ Caucasian: a first dose of $25 \mathrm{mg}$ at night to avoid sedation and orthostatic hypotension ${ }^{\mathrm{b}}$ If tolerated, $\uparrow$ daily dose by $25 \mathrm{mg}$, keeping approximately $2 / 3$ at night

Schedule $\uparrow$, avoiding major increases during times with less supervision (weekends).

Target $100 \mathrm{mg} /$ day at the end of the first week.

-Typical East Asian: ${ }^{\mathrm{c}}$ a first dose of $12.5 \mathrm{mg}$ at night to avoid sedation and orthostatic hypotension ${ }^{\mathrm{b}}$ If tolerated, $\uparrow$ daily dose by $12.5 \mathrm{mg}$, keeping approximately $2 / 3$ at night

Schedule $\uparrow$, avoiding major increases during times with less supervision (weekends).

Target $50 \mathrm{mg} / \mathrm{day}$ at the end of the first week.

\section{SECOND WEEK}

-Typical ${ }^{\mathrm{a}}$ Caucasian: if tolerated, $\uparrow$ twice $50 \mathrm{mg} /$ day each time, keeping approximately $2 / 3$ at night.

Target $200 \mathrm{mg} / \mathrm{day}$ at the end of the second week.

-Typical East Asian: ${ }^{\mathrm{c}}$ if tolerated, $\uparrow$ twice $25 \mathrm{mg}$ /day each time, keeping approximately $2 / 3$ at night. Target $100 \mathrm{mg} / \mathrm{day}$ at the end of the second week.

\section{THIRD WEEK}

-Typical ${ }^{\mathrm{a}}$ Caucasian: if tolerated, $\uparrow$ twice $50 \mathrm{mg} /$ day each time, keeping approximately $2 / 3$ at night. Target $300 \mathrm{mg} /$ day at the end of the third week.

-Typical East Asian: ${ }^{\mathrm{c}}$ if tolerated, $\uparrow$ twice $25 \mathrm{mg} /$ day each time, keeping approximately $2 / 3$ at night. Target $150 \mathrm{mg} /$ day at the end of the third week.

\section{FOURTH WEEK TDM}

-Caucasians on $300 \mathrm{mg} /$ day: $C=350 \mathrm{ng} / \mathrm{ml}$; $C / D$ ratio $=350 / 300=1.2$. Needs $\geq 300 \mathrm{mg} /$ day (better ${ }^{\mathrm{e}} 300-400 \mathrm{mg} /$ day). $\mathrm{C}=175 \mathrm{ng} / \mathrm{ml} ; \mathrm{C} / \mathrm{D}$ ratio $=175 / 300=0.6$. Needs $\geq 600 \mathrm{mg} /$ day $\left(\right.$ better $^{\mathrm{e}} 600-700 \mathrm{mg} /$ day) $\mathrm{C}=87 \mathrm{ng} / \mathrm{ml} ; \mathrm{C} / \mathrm{D}$ ratio $=87 / 300=0.3 .{ }^{\mathrm{f}}$ May need up to $900 \mathrm{mg} / \mathrm{day}$

-East Asians on $150 \mathrm{mg} /$ day: $\mathrm{C}=350 \mathrm{ng} / \mathrm{ml} ; \mathrm{C} / \mathrm{D}$ ratio $=350 / 150=2.4$. Needs $\geq 150 \mathrm{mg} /$ day (better ${ }^{\mathrm{e}} 150-200 \mathrm{mg} /$ day). $\mathrm{C}=175 \mathrm{ng} / \mathrm{ml} ; \mathrm{C} / \mathrm{D}$ ratio $=175 / 150=1.2$. Needs $\geq 300 \mathrm{mg} / \mathrm{day}$ (better ${ }^{\mathrm{e}} 300-400 \mathrm{mg} / \mathrm{day}$ ).

\section{FURTHER INCREASES IN PATIENTS NEEDING HIGHER DOSES}

-In Caucasians, $\uparrow$ twice $50 \mathrm{mg} /$ day each time with a target $\uparrow 100 \mathrm{mg} / \mathrm{week}$. After the fourth week, many patients can tolerate faster increases $(100 \mathrm{mg} / \mathrm{day})$; orthostatic problems usually do not occur. If you estimate needing doses $>600$ $\mathrm{mg} / \mathrm{day}$, try to re-estimate the dose required for $>350 \mathrm{ng} / \mathrm{ml}$ of clozapine $\mathrm{C}$, on $600 \mathrm{mg} /$ day dose.

-In East Asians, $\uparrow$ twice $25 \mathrm{mg} /$ day each time with a target $\uparrow 50 \mathrm{mg} / \mathrm{week}$.

\section{TARGET DOSES}

-One week after you reach your target dose, repeat TDM to verify $>350 \mathrm{ng} / \mathrm{ml}$ (better ${ }^{\mathrm{f}}$ if in $400 \mathrm{~s} \mathrm{ng} / \mathrm{ml}$ ).

-Whenever clozapine $\mathrm{C}$ reaches $>1000 \mathrm{ng} / \mathrm{ml}$, look for the reason and consider cutting the clozapine dose in half.

-Make the administration as easy as possible, including rounding doses and administering twice a day. ${ }^{g}$

-If you do not have access to clozapine TDM, best approximated recommendation:

Caucasians:

Female Caucasian non-smokers: around $300 \mathrm{mg} /$ day (100 early morning and 200 night).

Caucasian male non-smokers and female smokers: $300-600 \mathrm{mg} / \mathrm{day}$.

East Asians:

Male Caucasian smokers: around $600 \mathrm{mg} / \mathrm{day}$ (200 early morning and 400 night).

Female East Asian non-smokers: around $150 \mathrm{mg} / \mathrm{day}$ (50 early morning and 100 night).

East Asian male non-smokers and female smokers: $150-300 \mathrm{mg} / \mathrm{day}$.

East Asian male smokers: around $300 \mathrm{mg} / \mathrm{day}$ (100 early morning and 200 night).

\section{FURTHER NEED FOR TDM}

-If clinically relevant inducers or inhibitors are added or discontinued, repeat TDM after steady state is reached.

-Development of major inflammations or major infections ${ }^{\mathrm{h}}$ require close monitoring for ADRs. If TDM results take several days to arrive, you may want to cut the clozapine dose in half after collecting TDM.

-Remember major changes in smoking after a few (1-3) weeks may have relevant effects on clozapine C. Smoking cessation may $\uparrow$ clozapine $\mathrm{C}$ (approximately by a factor of 1.5 ). Restarting heavy smoking may $\downarrow$ clozapine $\mathrm{C}$ (approximately by a factor of 1.5 ).

-Watch for dramatic ${ }^{i}$ changes in caffeine intake.

LIMITATIONS OF THE RECOMENDATIONS (NEEDS UPDATING AS KNOWLEDGE EVOLVES)

-These recommendations are based on 1) experience with <200 patients started on clozapine by the last author; 2) a statistical model of clozapine dosing tested in US, Italian and Swiss samples, and 3) initial collaboration with Chinese researchers to review published Chinese literature and extend the statistical model to Chinese patients.

-Assuming that 1) the patient is taking clozapine correctly, 2) TDM is obtained correctly and 3) tested in a reliable laboratory, use $\mathrm{C} / \mathrm{D}$ ratio method rather than trusting dosing approximations from this table.

-Ask from help if you are not sure you understand the C/D ratio method. Pharmacists usually understand it better than physicians.

C: concentration; $\mathrm{C} / \mathrm{D}$ ratio: concentration/dose ratio; TDM: therapeutic drug monitoring. 


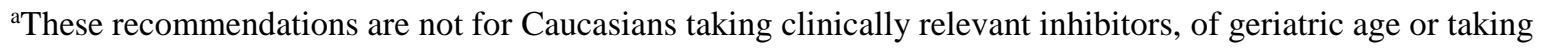
medication that increases clozapine risk due to pharmacodynamic drug interactions. For them, consider the titration recommended for East Asians.

${ }^{b}$ During titration, orthostatic changes in blood pressure and pulse need to be measured. Cut scores for abnormal values and a scale for documentation are provided by de Leon et al. (2009c). Orthostatic changes should be assessed before increasing any clozapine dose for at least the first 3 weeks. Orthostatic abnormalities or other ADRs should signal slower titration.

${ }^{\mathrm{c}}$ These are recommendations for CYP2C19 PMs, too, and are based on the literature review of clozapine C/D ratios in East Asians and CYP2C19 PMs having C/D ratios approximately twice as high. Consider slowing the titration for East Asians taking clinically relevant inhibitors, of geriatric age or taking medication that increase clozapine risk due to pharmacodynamic drug interactions.

${ }^{\mathrm{d} D r a w}$ trough clozapine $\mathrm{C}$ in the early AM at least one week after the last clozapine dose increase.

${ }^{\mathrm{e}}$ Fluctuations of $10 \%$ are not unusual in the same patient taking the same dose and using the same laboratory. A clozapine concentration result of around $350 \mathrm{ng} / \mathrm{ml}$ may be associated with risk of subtherapeutic concentrations on other days. Keeping a clozapine concentration in the $400 \mathrm{~s} \mathrm{ng} / \mathrm{ml}$ appears easy and safe.

${ }^{\mathrm{f}}$ Double-check as much as you can that non-compliance does not explain low clozapine concentration. Repeat TDM if you have any doubts about low clozapine $\mathrm{C}$.

gOccasionally a single dose at night facilitates compliance and can $\downarrow$ risks for ADRs unless the patient gets up in the middle of the night.

${ }^{\mathrm{h}}$ Major infections include pneumonias, upper respiratory infections with fever, pyelonephritis and appendicitis. iAlthough no prospective study defines what a "dramatic" change is, caution is recommended with increases or decreases of daily caffeine intake of $>1$ cup of coffee (or 2 cans of caffeinated sodas) in non-smokers and $>3$ cups (or 6 cans of caffeinated soda) in smokers. For example, when a smoker taking clozapine increases caffeine intake by three cups of coffee (e.g., from 2 to 5 cups per day), clinicians should watch for increased side effects due to $\uparrow$ clozapine $C$. 


\section{$R$ versus 9-hydroxyrisperidone (9-OHR)}

-9-OHR has similar in vitro $\mathrm{D}_{2}$ affinity but probably lower brain penetrance due to higher P-gp affinity. Oral paliperidone (9-OHR) requires higher doses, approximately twice that of oral $\mathrm{R}$ doses. ${ }^{\mathrm{a}}$

\section{R pharmacokinetics}

-CYP2D6 is the main metabolic enzyme for R. CYP3A4 can transform R to 9-OHR but is less efficient. -CYP3A4 probably metabolizes both $\mathrm{R}$ and 9-OHR.

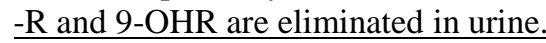

\section{1) Subjects requiring higher doses:}

Genetic, environmental or personal factors leading to the need for high or low $\mathbf{R}$ doses

-Patients taking CYP3A4 inducers. When potent CYP3A4 inducers dramatically increase CYP3A4 levels, this enzyme becomes more important and there are parallel $\uparrow$ in $\mathrm{R}$ and $9-\mathrm{OH}$ metabolisms.

-It is possible but not definitively demonstrated for CYP2D6 UMs (who have $\geq 3$ active copies of CYP2D6).

-Pregnancy effects on R metabolism have not been studied but it is expected to $\uparrow$ CYP2D6 and $\uparrow$ CYP3A4 activity.

2) Subjects requiring lower doses:

-CYP2D6 and CYP3A4 inhibitors $\downarrow$ R elimination. Fluoxetine is particularly powerful since it is a potent CYP2D6

inhibitor and its metabolite, norfluoxetine, has inhibitory CYP3A4 properties.

-Geriatric age and renal insufficiency will $\downarrow$ the renal elimination of R and 9-OHR.

-Brain changes may produce pharmacodynamic changes that may require using lower $\mathrm{R}$ doses. Demented patients and adults with intellectual disability may not tolerate $\mathrm{R}$ doses and serum total concentrations as well as other patients.

Naive patients, never exposed to antipsychotics, may not tolerate $\mathrm{R}$ as well as patients exposed to antipsychotics. ${ }^{\mathrm{c}}$

\section{R/9-OH ratio}

Calculation: Divide R by 9-OHR concentration.

Meaning: Index of CYP2D6 activity.

Values per genotyping: ${ }^{\mathrm{d}} \mathrm{UM}$ ( 3 active alleles):

EM (1-2 active alleles):

IM $(>0$ but $<1)$ :

PM (0)

around 0.03

around 0.08

$0.30-1.0$ depending on alleles

2.5 (1.8 to 4.1$)$

$\mathrm{R} / 9-\mathrm{OH}$ ratio $>1$ (called inverted ratios since $\mathrm{R}>9-\mathrm{OHR}^{\mathrm{e}}$ ) indicate a CYP2D6 PM or patient is taking a powerful CYP2D6 inhibitor (fluoxetine or paroxetine). Remember CYP2D6 PMs eliminate R poorly. IMs with R/9-OH ratio close to 1 in the absence of inhibitors (e.g., East Asians with CYP2D6*10/10) may also have problems eliminating R. C/D ratio

Calculation: Divide the total concentration $(\mathrm{R}+\mathrm{OHR})^{\mathrm{f}}$ in $\mathrm{ng} / \mathrm{ml}$ by $\mathrm{R}$ dose in $\mathrm{mg} / \mathrm{day}$.

Meaning: Index of total ability to eliminate R by using CYP2D6, CYP3A and renal excretion.

Normal values: 7 in US research ${ }^{\mathrm{g}}$ and clinical laboratories. ${ }^{\mathrm{h}}$

10 in Italian research laboratory. ${ }^{\mathrm{i}}$

Differences may be due to different analytic techniques and/or calibrations.

Each laboratory needs to establish its normal C/D

C/D < half of normal: increased ability to eliminate $\mathrm{R}$ (if the patient is compliant)

( $<7$ in the US) can be explained by: CYP3A4 inducers (if the patient is compliant)

$(<10$ in the Italian lab)

C/D > twice normal: poor ability to eliminate $R$

(>14 in US) can be explained by: CYP2D6 PM genotype,

(>20 Italian lab) use of CYP2D6 inhibitors or CYP3A inhibitors

renal insufficiency (limited clinical experience)

9-OHR: 9-hydroxyrisperidone. C/D: concentration/dose ratio. CYP2D6: cytochrome P450; $\mathrm{D}_{2}$ : dopamine 2 receptor; EM: extensive metabolizer; P-gp: p-glycoprotein; PM: poor metabolizer; R: risperidone; TDM: therapeutic drug monitoring.

ade Leon et al. 2010

bIt is possible that pregnancy, as it progresses to the third trimester, may decrease total risperidone C/D ratio by $\uparrow$ CYP2D6 and CYP3A4 activity. Although there are no published studies of risperidone pharmacokinetics during pregnancy, pregnancy is definitively associated with $\uparrow$ CYP2D6 and $\uparrow$ CYP3A4 activity (Gaohua et al. 2012).

'de Leon et al. 2008.

${ }^{\mathrm{d}}$ See Table 6 in de Leon et al. 2009c.

'Ereshefsky 1996.

${ }^{\mathrm{f}}$ This ignores minor differences in molecular weights of R and 9-OHR. More importantly, it does not take into account the possibility that 9-OHR may have lower brain penetrance (de Leon et al. 2010).

gde Leon et al. 2007.

hBork et al. 1999.

iScordo et al. 1999. 
Table 7. Current approximations for personalizing risperidone dosing in the absence of TDM for average adults not taking any other antipsychotic ${ }^{\text {a }}$ by combining pharmacodynamic and pharmacokinetic influences

\begin{tabular}{|c|c|c|c|c|c|}
\hline & & & $\begin{array}{l}\text { Carbamazepine } \\
\text { and other inducers }\end{array}$ & CYP2D6 PMs & $\begin{array}{l}\text { Fluoxetine } \\
\text { and other inhibitors }\end{array}$ \\
\hline & & Normal & (multiply x 2) & (divide by 2 ) & (divide by 1.3 ) \\
\hline DOSES $(\mathrm{mg} / \mathrm{d}$ & & & & & \\
\hline Average adult & Starting $^{\mathrm{d}}$ & $1-2$ & $2-4$ & $0.5-1$ & $0.75-1.5$ \\
\hline & Target $^{\mathrm{e}}$ & 4 & 8 & 2 & 3 \\
\hline & Maximum $^{\mathrm{f}}$ & 6 & 12 & 3 & 4 \\
\hline First psychotic & Starting $^{\mathrm{d}}$ & 1 & 2 & 0.5 & 0.75 \\
\hline Episode ${ }^{\mathrm{g}}$ & Target $\mathrm{e}^{\mathrm{e}}$ & 2 & 4 & 1 & 1.5 \\
\hline & Maximum $^{\mathrm{f}}$ & 4 & 8 & 2 & 3 \\
\hline Geriatric & Starting $^{\mathrm{d}}$ & 0.25 & 0.5 & 0.12 & 0.12 \\
\hline renal/liver ${ }^{\mathrm{h}}$ & Target $\mathrm{e}^{\mathrm{e}}$ & 2 & 4 & 1 & 1.5 \\
\hline $\begin{array}{l}\text { insufficiency } \\
\text { or any brain } \\
\text { organicity }\end{array}$ & Maximum $^{\mathrm{f}}$ & 4 & 8 & 2 & 3 \\
\hline Demented & Starting $^{\mathrm{d}}$ & 0.5 & 1 & 0.25 & 0.25 \\
\hline & Target $^{\mathrm{e}}$ & 1 & 2 & 0.5 & 0.75 \\
\hline & Maximum $^{\mathrm{f}}$ & 1.5 & 3 & 0.75 & 1 \\
\hline Adult ID & Starting $^{\mathrm{d}}$ & $1-2$ & $2-4$ & $0.5-1$ & $0.75-1.5$ \\
\hline behaviors $^{\mathrm{i}}$ & Target $\mathrm{e}^{\mathrm{e}}$ & 2 & 4 & 1 & 1.5 \\
\hline & Maximum $^{\mathrm{f}}$ & 4 & 8 & 2 & 3 \\
\hline
\end{tabular}

CYP2D6: cytochrome 2D6. ID: intellectual disability. P-gp: p-glycoprotein; PM: poor metabolizer. TDM: therapeutic drug monitoring.

This table is based on Table 1 published in de Leon et al. (2008) but substantial modifications were made to clarify the table and only focus on adults.

aIf the patient is taking another antipsychotic, lower risperidone doses than those described in this table should be used as long as the other antipsychotic is prescribed. If the patient has taken risperidone, prior doses can be used for orientation as long there are no changes in co-prescription of inhibitors or inducers, development of renal or hepatic insufficiency or becoming a geriatric patient. TDM can provide a better approximation for an individual than these average recommendations.

${ }^{\text {b}}$ These indications are based mainly on carbamazepine data. Other CYP3A inducers have not been well studied. Clinically relevant inducers that may have similar or greater effects than carbamazepine are rifampin, phenobarbital, primidone, phenytoin, nonnucleoside reverse transcript inhibitors (efavirenz and delavirdine). Mild inducers that are probably less potent than carbamazepine are oxcarbazepine, dexamethasone, prednisone and St. John's wort. Mild inducers have not been studied.

'Inhibitors include CYP2D6 inhibitors other than fluoxetine: paroxetine, duloxetine, bupropion, and any potent CYP3A inhibitor: fluvoxamine, cimetidine, ketoconazole, erythromycin, clarithromycin, protease inhibitors, grapefruit juice, and diltiazem. High doses of sertraline may also be an inhibitor of R metabolism. Verapamil in high doses, a PgP inhibitor, may also negatively influence R metabolism. Disregard inhibitor effects if the patient is taking potent inducers.

${ }^{\mathrm{d} S t a r t i n g ~ d o s e}$ refers to the first dose given to the patient. This dose has to be slowly titrated over a few days based on tolerance to reach the target dose. Lower starting doses are recommended to avoid orthostatic hypotension and other adverse drug reactions to the first risperidone doses.

eTarget dose refers to the dose expected to be therapeutic in the average patient with these specific characteristics. ${ }^{f}$ Maximum dose refers to the maximum recommended dose expected in the average patient with these specific characteristics.

${ }^{\text {g} F i r s t-e p i s o d e ~ p a t i e n t s ~ a r e ~ p r o b a b l y ~ l e s s ~ t o l e r a n t ~ o f ~ r i s p e r i d o n e ~ a n d ~ o t h e r ~ h i g h ~ p o t e n t ~ a n t i p s y c h o t i c s, ~ s u c h ~ a s ~ h a l o p e r i d o l ~}$ (de Leon et al. 2008).

hPublished information on renal insufficiency is limited. There is no published information on hepatic insufficiency but conservative dosing appears reasonable.

iThese doses are for challenging behaviors that did not respond to non-pharmacological interventions. Psychotic episodes in adults with IDs may require higher doses; see average doses for adults. 